\title{
Comparison of COSMIC-2 radio occultation retrievals with RS41 and RS92 radiosonde humidity and temperature measurements
}

\author{
Xi Shao ${ }^{1, *}$, Shu-Peng $\mathrm{Ho}^{2}$, Bin Zhang ${ }^{1}$, Xinjia Zhou ${ }^{3}$, Stanislav Kireev ${ }^{3}$, Yong Chen ${ }^{2}$, and \\ Changyong $\mathrm{Cao}^{2}$ \\ ${ }^{1}$ Cooperative Institute for Satellite Earth System Studies (CISESS), Earth System Science Interdisciplinary Center, \\ University of Maryland, MD, USA \\ ${ }^{2}$ NOAA National Environmental Satellite, Data, and Information Service, Center for Satellite Applications and Research, MD, \\ USA \\ ${ }^{3}$ Global Science \& Technology, Inc., MD, USA
}

\begin{abstract}
Article history:
Received 26 May 2021

Revised 13 December 2021

Accepted 30 December 2021
\end{abstract}

Keywords:

COMISC-2, Vaisala RS41 and RS92, Radiosonde, Atmospheric temperature, Water vapor

\section{Citation:}

Shao, X., S.-P. Ho, B. Zhang, X. Zhou, S. Kireev, Y. Chen, and C. Cao, 2021: Comparison of COSMIC-2 radio occultation retrievals with $\mathrm{RS} 41$ and RS92 radiosonde humidity and temperature measurements. Terr. Atmos. Ocean. Sci., 32, 1015-1032, doi: 10.3319/TAO.2021.12.30.02

\begin{abstract}
Understanding the bias and uncertainty between radio occultation (RO) retrievals and radiosonde observations (RAOBs) impacts climate studies and numerical weather predictions. In this study, the temperature and humidity data independently retrieved by University Corporation for Atmospheric Research (UCAR) and NOAA Center for Satellite Applications and Research (STAR) from COSMIC-2 RO data are compared with in-situ Vaisala RS41 and RS92 RAOB data. Collocated 7-month of COSMIC-2 RO and RS41/RS92 RAOB data are analyzed to investigate the height and day-night dependence of temperature and humidity biases. It is found that UCAR and NOAA/STAR COSMIC-2 temperature retrievals are consistent above $12.5 \mathrm{~km}$. There are warm biases in RS92 data compared to RS41 data over the height region above $17.8 \mathrm{~km}$, mainly due to the warm daytime bias in RS92 data. The main temperature difference between UCAR and NOAA/STAR retrievals is $\sim 0.1-0.2 \mathrm{~K}$ over $8-11 \mathrm{~km}$, due to differences in the variational retrieval algorithms. Over $8-11 \mathrm{~km}$, the relative temperature difference between COSMIC-2 retrievals and RS41/RS92 RAOBs are more significant than other heights. The UCAR and NOAA/STAR COSMIC-2 humidity retrievals generally consist in the troposphere, especially above $4.8 \mathrm{~km}$. There are systematic wet biases below $4.2 \mathrm{~km}$ in the RO retrievals relative to RAOB humidity data. The COSMIC-2 retrieval and RS92 RAOB comparison show a clear day-night humidity bias difference below $4.2 \mathrm{~km}$ due to slight dry biases in the daytime RS92 data. The RO versus RAOB comparison helps quantify the temperature and humidity biases among different radiosonde sensor types and different $\mathrm{RO}$ retrieval algorithms.
\end{abstract}

\section{INTRODUCTION}

Long-term consistent atmospheric temperature climate data records (CDRs) with accurate uncertainty estimates are critical for detecting climate changes and understanding their feedbacks in the troposphere and stratosphere (Seidel et al. 2009; Thorne et al. 2011). Water vapor is one of the most important greenhouse gases in the atmosphere (Solomon et al. 2007). The trapping effect of water vapor in the air plays a crucial role in climate change (Forster et al.

\footnotetext{
* Corresponding author

E-mail:xshao@umd.edu
}

2007). Accurate and consistent water vapor measurements in the troposphere are essential for studying water vapor feedback on clouds and hydrological cycles, which are still among the most significant uncertainties in understanding climate change (Solomon et al. 2007). Radiosonde observations (RAOBs) have provided long-term in situ operational measurements of global atmospheric pressure, temperature, humidity, and wind in the troposphere and lower stratosphere for decades, making RAOBs the backbone observation system for both numerical weather prediction (NWP) and climate monitoring.

RAOB temperature measurements have been used to 
construct long-term CDRs and moisture climatology (e.g., Haimberger et al. 2008; Sherwood et al. 2008; Seidel et al. 2009; Haimberger and Andrae 2011; Thorne et al. 2011). However, the quality of radiosonde temperature and moisture measurement varies for different sensor types, heights, and changes in environmental conditions primarily due to the influence of solar and infrared radiation on the thermistor (e.g., Gaffen 1994; Luers and Eskridge 1995, 1998; Luers 1997; Haimberger et al. 2008; Sun et al. 2013). To correct the RAOB solar/infrared radiation errors, the manufacturers introduced radiation correction tables for specific radiosonde types. Also, various statistical, laboratory, or physical-based correction schemes have been developed to correct known RAOB temperatures and humidity observational errors for the individual types of radiosondes (Leiterer et al. 1997; Wang et al. 2002; Turner et al. 2003; Andrae et al. 2004; Haimberger 2007; Vömel et al. 2007; Haimberger et al. 2008).

However, due to a lack of benchmark temperature and humidity references, it is difficult to quantify the remaining radiation temperature biases and possible geographically and temporally dependent errors even after applying corrections (e.g., Gaffen 1994; Haimberger et al. 2008; Ho et al. 2010a; Sun et al. 2013). Therefore, the significant uncertainties among long-term temperature CDRs and moisture climatology constructed from satellite and in situ radiosonde measurements are still among the most challenging issues for climate change research.

All-weather temperature and water vapor profiles can be obtained from Global Positioning System (GPS) radio occultation (RO) data (Anthes et al. 2000; Kursinski and Hajj 2001; Ho et al. 2009a, b, 2010b). Because the quality of RO data does not change during the day or night and is not affected by clouds (Anthes et al. 2008; Ho et al. 2020a), the RO temperature and water vapor profiles co-located with RAOBs are useful for identifying the variation of temperature and humidity biases over time. In the past, atmospheric variables such as temperature and humidity profiles retrieved from Constellation Observing System for Meteorology, Ionosphere, and Climate and Formosa Satellite Mission 3 (hereafter COSMIC-1) and METOP GRAS have been used as references to identify RAOB sensor-dependent biases. For example, He et al. (2009), Sun et al. (2010, 2013, 2019), and Ho et al. (2020a, b) used RO temperature data in the lower stratosphere to quantify the temperature biases for several RAOB sensor types. Ho et al. (2010a) demonstrated that RO-derived water vapor profiles could be used to distinguish systematic biases among humidity sensors of RAOB.

As the follow-on mission of the COSMIC-1 mission, the COSMIC-2/FORMOSAT-7 constellation with six satellites was successfully launched into a 24-degree inclination low Earth orbit on 25 June 2019. COSMIC-2 is an international and inter-agency RO mission with the program participants from NOAA (National Oceanic and Atmospheric
Administration), U.S. Air Force (USAF), Taiwan's National Space Organization (NSPO), and the University Corporation for Atmospheric Research (UCAR). The UCAR COSMIC Data Archive Center (CDAAC) is the COSMIC-2 data processing center (DPC). The NOAA National Environmental Satellite, Data, and Information Service (NESDIS) Center for Satellite Applications and Research (STAR) provides validation and quality monitoring of COSMIC-2 data. NOAA/STAR also processes COSMIC-2 data independently through post-processing to evaluate the impact of different implementations of processing algorithms on the RO data quality (Ho et al. 2020b).

Each of the six satellites in the COSMIC-2 constellation has the primary Tri-GNSS Radio-occultation System (TGRS) payload for RO measurements. The TGRS was designed with a steering beam-phase array antenna and advanced receiver to receive navigation signals from multiple Global Navigation Satellite System (GNSS) satellites such as the US Global Positioning System (GPS), the European Galileo system, and the Russian GLONASS (GLObal NAvigation Satellite System). Such a design enhances RO signal quality with a higher Signal-to-Noise Ratio (SNR) and deeper penetration depth, increasing the number of successful RO retrievals, especially in the lower tropical troposphere (Cao et al. 2020; Ho et al. 2020b; Schreiner et al. 2020; Chen et al. 2021a, b; Shao et al. 2021). COSMIC-2 occultations mainly distribute from $45^{\circ} \mathrm{N}$ and $45^{\circ} \mathrm{S}$. COSMIC- 2 is the first RO sensor that provides routine GLONASS GNSSRO measurements for operational NWP applications. It routinely offers atmospheric and ionospheric data to daily near-real-time weather forecasts, climate studies, and space weather applications.

While the time delays and carrier phases derived from the GNSS RO satellite remote sensing measurements are traceable to the international standard of units (SI traceability), the derived temperature and humidity profiles can vary with different processing modules. These RO-retrieved temperature and humidity profiles are often used to evaluate the quality of other atmospheric measurements such as RAOB (Ho et al. 2010a, b, 2017, 2020a; Sun et al. 2013, 2019), microwave (Ho et al. 2009b), and infrared sounding measurements (Ho and Peng 2019; Xue et al. 2019). To retrieve temperature and moisture profiles in the troposphere and lower stratosphere from RO data, variational algorithms are used to invert the $\mathrm{RO}$ refractivity profiles (Ho et al. 2022). To process COSMIC-2 RO data, UCAR and NOAA/ STAR have independently developed one-dimensional variational (1DVAR) retrieval algorithms to convert the COSMIC-2 refractivity into vertical temperature and moisture profiles (wet profiles). In particular, the 1DVAR retrieval of two variables, e.g., the humidity and temperature in the troposphere, from a single quantity such as refractivity is an under-determined inversion problem. The a priori atmospheric model needs to decouple moisture and temperature 
information from the refractivity profiles. Therefore, the differences in the setup of background error covariance to characterize the monthly variability of atmospheric temperature and humidity profiles, the setup of observation error covariance of measurement noise, a priori (first guess) model, and the relative constraints applied to the allowable deviation from the observation and correspondence to the $a$ priori in the 1DVAR retrieval can affect the accuracy and the uncertainty of retrieval products at different heights. Therefore, it is crucial to understand and evaluate the consistency and difference of COSMIC-2 temperature and humidity data processed by different retrieval algorithms such as those from UCAR and NOAA/STAR.

With up to $5000 \mathrm{RO}$ profiles of high vertical resolution and uniformly distributed in time and space within $30^{\circ} \mathrm{N}$ to $30^{\circ} \mathrm{S}$ (Ho et al. 2020b), COSMIC-2 provides a unique opportunity to compare RO-retrieved mid to low latitude temperature and water vapor data with RAOB measurements in the tropical and sub-tropical regions. In the upper troposphere and lower stratosphere regions, although moisture exists, the contribution of moisture to refractivity measurement is minimal. Therefore, the focus of the comparison is on the temperature between COSMIC-2 and RS41/RS92 RAOB over the height region above $8 \mathrm{~km}$. In the troposphere, humidity changes rapidly as approaches the surface, and humidity contributes more to refractivity measurements than the temperature. Due to the under-determined nature of retrieving two variables (temperature and humidity) from one observable, such as refractivity in the 1DVAR retrieval, RO retrievals' humidity and temperature are coupled. The temperature retrievals can be affected more by the a priori model than the humidity in the lower troposphere in the IDVAR. Therefore, this study quantifies the humidity biases and uncertainties over the height region below $8.4 \mathrm{~km}$.

The focus of this research is on the relative inter-consistency among RAOB measurements and COSMIC-2 retrievals. Instead of assuming that either RO or RAOB is the truth over all heights for both temperature and humidity products, we point out that such consistency varies over height regions and day or night time conditions. Therefore, the objective of this study is two-fold. First, we will use temperature and humidity data derived from the COSMIC- 2 to characterize and compare the variability of temperature biases in the upper troposphere and lower stratosphere and humidity biases in the troposphere with different types of radiosonde sensors, namely, Vaisala RS41 and RS92. Vaisala RS92 was a primary radiosonde type in the global operational upper-air network over two decades (Bodeker et al. 2016). Starting in late 2013, RS92 was gradually replaced by Vaisala RS41. Vaisala RS41 is expected to provide a more accurate measurement of atmospheric temperature, humidity with improved precision. Both RS92 and RS41 radiosondes provided the backbone temperature and moisture measurements for NWP and satellite-based sounding senor validation. COSMIC-2
RO data also offer a unique opportunity to serve as a reference to characterize and understand the height and solar zenith angle (SZA)-dependence of biases and uncertainties of Vaisala RS41 and RS92 radiosonde measurements.

Secondly, we will also use in-situ RAOB sensor measurements to examine COSMIC-2 neutral atmospheric profiles' quality. Ho et al. (2009a) have quantified the quality of RS92 using COSMIC data. The temperature difference between RS92 and COSMIC in the lower stratosphere is within $+/-0.1 \mathrm{~K}$. The consistent RAOB measurements over a certain height and SZA range can serve as references to determine the height and SZA-dependence of the consistency and difference between UCAR and NOAA/STAR COSMIC-2 wet profile retrievals. We will assess the accuracy and uncertainty of COSMIC-2 temperature in the upper troposphere and lower stratosphere and moisture in the troposphere.

In the following sections, the COSMIC-2 wet profile datasets and RAOB datasets used in this study are described in sections 2.1 and 2.2, respectively. Section 2.3 presents the collocation-based comparison method. The overall comparison of UCAR and NOAA/STAR COSMIC-2 temperature and water vapor profiles with RS41 and RS92 RAOB measurements is shown in section 3.1. Sections 3.2 and 3.3 offer the evaluation of day/night differences of temperature and humidity biases between COSMIC-2 and RAOB, respectively. Conclusions are presented in section 4 .

\section{RAOB AND COSMIC-2 DATA AND ANALYSIS METHODOLOGY}

\subsection{Vaisala RS41 and RS92 RAOB Data}

RAOBs provide long-term global in situ temperature, moisture, and wind measurements in the troposphere and lower stratosphere. Radiosonde measurements have been ingested to construct atmospheric temperature CDRs and moisture climatology to understand climate variability and change in the troposphere and stratosphere and their feedback mechanisms (Seidel et al. 2009; Thorne et al. 2011). Long-term stable and consistent RAOBs with accurate uncertainty estimates are critical to the climate trend detection, NWP, and satellite-based atmospheric sounding measurement communities.

However, it has long been recognized that the RAOB measurement quality varies for different sensor types, altitude, and solar elevation angle (e.g., Luers and Eskridge 1995, 1998; Luers 1997). The causes of temperature and humidity measurement uncertainties for RAOB sensors include solar and infrared radiation on the thermistor, air friction correlated with balloon speed and air density, and changing environment. RAOB sensor-specific correction schemes were derived using limited data by considering minor factors such as pressure, solar elevation angle, and balloon ascent speed. Due to a lack of stable and accurate 
references, it was reported (Gaffen 1994; Haimberger et al. 2008; Sherwood et al. 2008; Ho et al. 2010a; Sun et al. 2013) that the temperature and moisture measurement errors remain in RAOB data even after the correction. In particular, radiosonde measurements' uncertainty and accuracy vary with different sensor types, making the long-term temperature CDRs and moisture climatology still subject to significant uncertainty.

Therefore, it is essential to understand the RAOB-related temperature and humidity biases through comparisons with other data. This paper focused on analyzing and evaluating the quality of temperature and humidity data of two types of RAOBs, namely Vaisala RS41 and RS92 sonde, through comparison with collocated COSMIC-2 RO retrievals.

The RS41 and RS92 radiosonde data used in this study were downloaded from the NCAR data archive (https://rda. ucar.edu/datasets/ds351.0/). The data include the pressure, geopotential height, air temperature, dew point temperature, wind direction, and speed at up to 20 mandatory levels from 1000 millibars to 1 millibar, plus a few significant pressure levels. These radiosonde data generate atmospheric temperature, pressure, and moisture profiles together with the exact radiosonde types. Figure 1 depicts the geophysical locations for RS41 and RS92 data from October 2019 to April 2020, collocated with COSMIC-2 RO data and analyzed in this study. There are relatively fewer collocated RS92 stations than RS41 stations.

Vaisala RS92 was a primary radiosonde type in the global operational upper-air network and provided the backbone temperature and moisture measurements for NWP and satellite-based sounding senor validation. Over the past two decades, RS92 was used as a reference sonde in the Global Climate Observing System (GCOS) Reference Upper-Air Network (GRUAN; Bodeker et al. 2016). RS92 was the workhorse of GRUAN before 2017. Vaisala RS41 (https://www.vaisala.com/en/products/instruments-sensors- and-other-measurement-devices/soundings-products/rs41) is equipped with an advanced platinum resistor-based temperature sensor. Its humidity sensor is based on a thin-film capacitor with an internal temperature sensor. Vaisala RS41 improves measurement accuracy for temperature, humidity, and other variables such as pressure and wind parameters throughout the atmosphere. Vaisala RS41 replaced RS92 in late 2013 and is currently the dominant radiosondes used by GRUAN stations.

Several earlier works (He et al. 2009; Ho et al. 2010a; Jensen et al. 2016; Kawai et al. 2017; Sun et al. 2019) have studied the data quality of RS92 and RS41. In addition, they are using different methods such as analyzing duallaunch data of RS41 and RS92 or use the RAOB-collocated RO data as the reference. It was found (Jauhiainen et al. 2014; Jensen et al. 2016; Kawai et al. 2017) that the temperature measurement precision in the lower stratosphere (above $100 \mathrm{hPa}$ ) is within 0.15 and $0.2 \mathrm{~K}$ for RS41 and RS92, respectively. Below $100 \mathrm{hPa}$, the precision of RS41 temperature measurement is within $0.3 \mathrm{~K}$. As a comparison, the temperature precision of RS92 is within $0.5 \mathrm{~K}$ below $100 \mathrm{hPa}$. The RS92 has a $\sim 0.1 \mathrm{~K}$ warm temperature bias above $100 \mathrm{hPa}$ from the COSMIC-RS92 temperature comparison over $60^{\circ} \mathrm{S}$ to $60^{\circ} \mathrm{N}$ latitude regions (Ho et al. 2010b). The altitude-dependent humidity difference between RS41 and RS92 is, in general, within 4\% at pressure $>200 \mathrm{hPa}$ or equivalently at altitudes below $\sim 11.8 \mathrm{~km}$ (Kawai et al. 2017). The mean difference between RS41 and RS92 humidity at altitudes below $\sim 11.8 \mathrm{~km}$ is $\sim 2 \%$. The COSMIC-2 RO retrievals provide more temperature and humidity profiles than COSMIC-1 in the tropical region with higher SNR and deeper penetration depth. They can serve as stable and accurate temperature references in the lower stratosphere and humidity references in the lower troposphere. It offers opportunities to understand and characterize the measurement accuracy and uncertainty of RS92

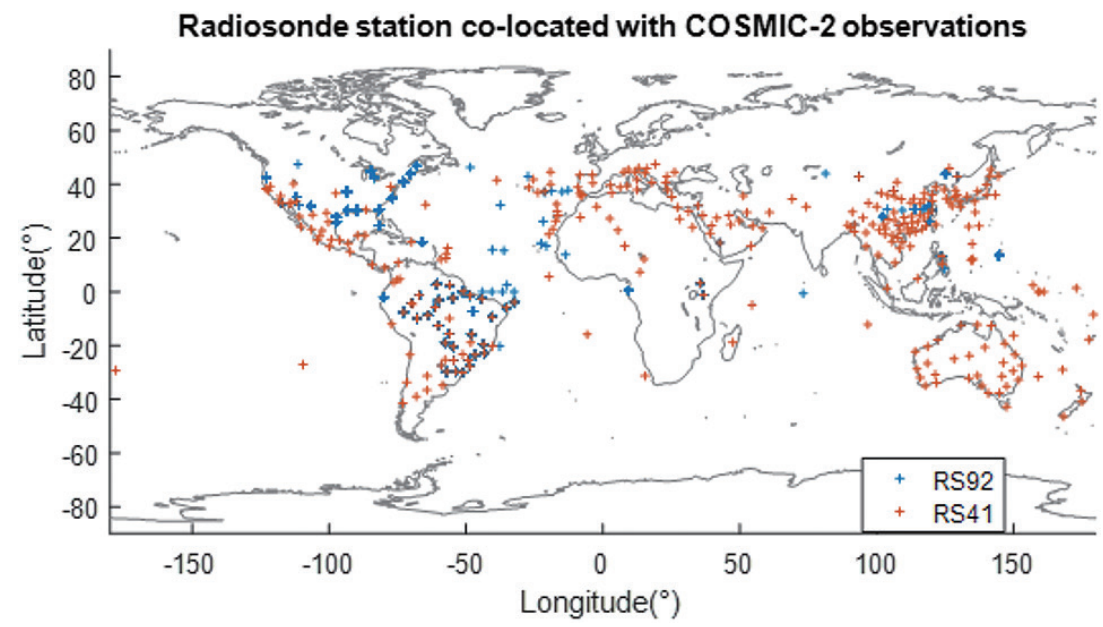

Fig. 1. Global distribution of RS41 and RS92 stations with colors indicating different radiosonde types. 
and RS41 radiosondes. This study evaluates the height and day/night dependence of uncertainty and accuracy of RS41 and RS92 RAOB temperature and humidity data by comparing with COSMIC-2 RO retrieval products.

\subsection{COSMIC-2 RO Retrieval Products}

COSMIC-2 provides comprehensive coverage of occultations in low and mid-latitude regions, i.e., from $45^{\circ} \mathrm{N}$ and $45^{\circ} \mathrm{S}$. Through the combination of high-performance GPS+GLONASS receiver and steering beam antenna design, COSMIC-2 increases the number of successful RO retrievals per satellite and enhances the GNSS-RO measurement quality with higher SNR and improved penetration depth in the tropical troposphere (Ho et al. 2020b; Schreiner et al. 2020).

Figure 2 shows the penetration depth above mean sea level (MSL) for COSMIC-2 occultations over the ocean and land as a function of SNR, i.e., L1 SNR at $80 \mathrm{~km}$, compared with other RO sensors as COSMIC-1, KOMPSAT-5 (Korean Multi-purpose Satellite 5) and TSR-X (TerraSAR-X). Here the penetration depth is defined as the cut-off retrieval height above ground level. The SNR-dependent penetration depth over land and ocean shows that COSMIC-2 produces more than twice higher SNR values than any previous RO missions. Over land, due to the impacts of terrain altitudes, the penetration depth is in most cases above MSL height = $1 \mathrm{~km}$ and reaches below $1 \mathrm{~km}$ when SNR > $2500 \mathrm{v} / \mathrm{v}$. Over the ocean, the penetration depth of COSMIC-2 is below $0.5 \mathrm{~km}$ for SNR > $1250 \mathrm{v} / \mathrm{v}$. In general, the higher SNR of COSMIC-2 allows quantitatively more profiles with deeper penetrations over both land and ocean than previous RO sensors (also see Ho et al. 2020b).

The six small satellites in the COSMIC- 2 constellation provide as much as $\sim 5000 \mathrm{RO}$ measurements per day. On 16 March 2020, COSMIC-2 RO data were available to the public for atmospheric and climate studies and NWP applications. Early evaluation of COSMIC-2 data quality shows compatible stability, precision, accuracy, and uncertainty regarding accuracy with those from COSMIC-1 (Ho et al. 2020b). The assimilations of COSMIC-2 data into the NWP systems show positive impacts of COSMIC-2 RO data at higher troposphere and lower stratosphere on weather predictions (Healy 2020; Shao 2020). Because more than $85 \%$ of COSMIC-2 data were cut off after quality control (QC), much less COSMIC-2 impacts were found in the current EMC NWP system (see section 5 in Ho et al. 2022; Healy 2020; Shao 2020).

To invert the fundamental observable (time delay) for $\mathrm{RO}$ occultations to the temperature and moisture profiles in the troposphere and lower stratosphere, an IDVAR inversion approach needs to be developed and applied to resolve the ambiguity of RO refractivity associated with both temperature and water vapor in the lower troposphere. Both UCAR and NOAA/STAR have independently developed 1DVAR retrieval algorithms to retrieve optimal temperature
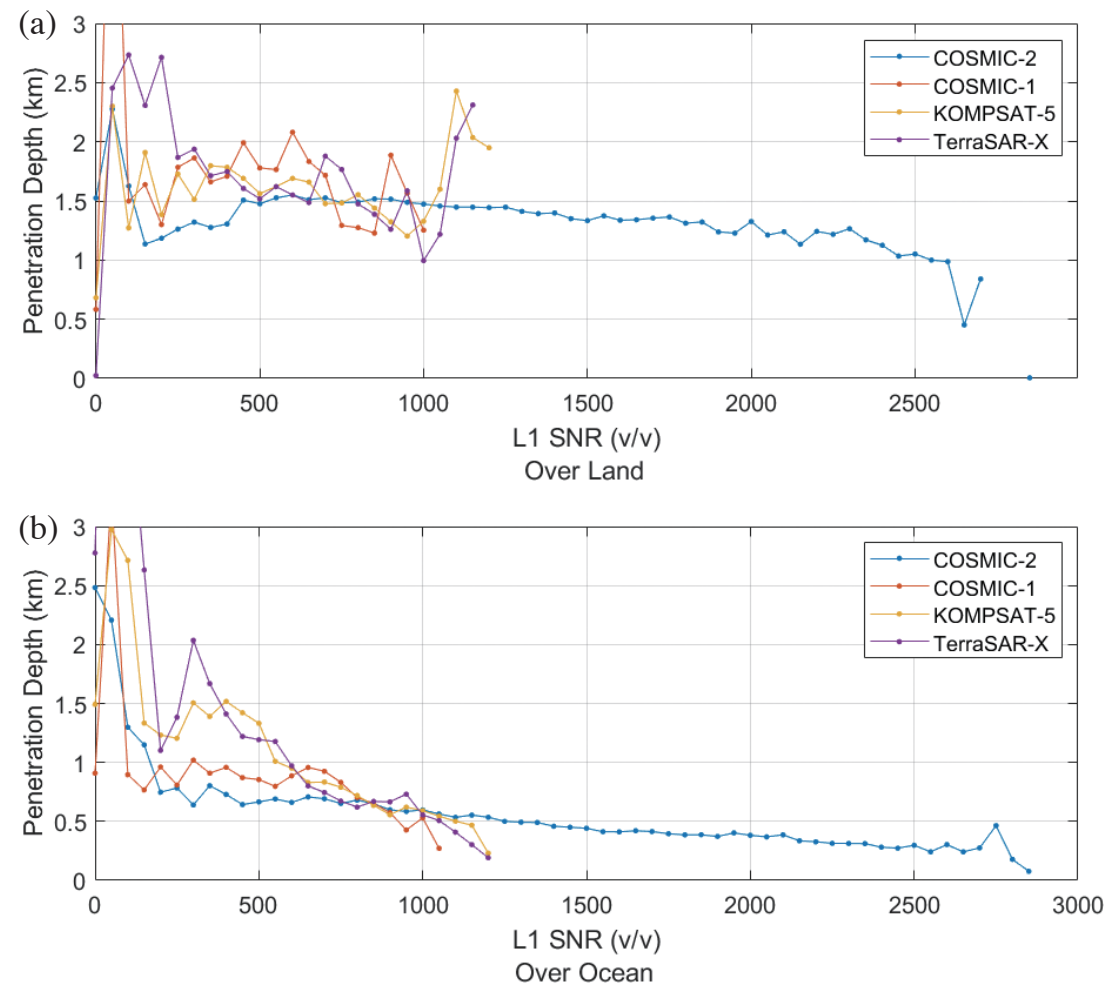

Fig. 2. Penetration depths as functions of L1 SNR over (a) land and (b) ocean for multiple RO missions. 
and humidity profiles from COSMIC-2 RO refractivity profiles. In this study, we analyzed two versions of wet profile data (see Table 1) that are produced by UCAR, namely UCAR wetPf2 (https://data.cosmic.ucar.edu/gnss-ro/cosmic2/nrt/), and by NOAA/STAR, namely NOAA/STAR wetPrf (ftp://ftp.star.nesdis.noaa.gov/pub/smcd/scda/GNSSRO/COSMIC2/wetPrf/).

In the official release of COSMIC-2 RO data in October 2019, UCAR implemented the wetPf2 1DVAR retrieval algorithm (Wee 2018) to process COSMIC-2 data. The features of the UCAR wetPf2 1DVAR retrieval algorithm include the use of statistical observation error, consistent background error with correlations to multi-variate, and ECM (Error Covariance Matrix) with higher spatial $\left(10^{\circ} \times 10^{\circ}\right)$ and temporal (monthly) resolution in comparison with the previous ECM with limited three latitudes and four seasonal dependence (Wee 2018). The wetPf2 retrieval algorithm also implemented variational Abel transform for bending angle optimization and considered terrain variation by incorporating a digital elevation model. Wee (2018) stated that to reduce the refractivity bias impact to the retrievals due to the possible super-refraction condition, and the wetPf 2 water vapor profiles may substantially fit the background below $2 \mathrm{~km}$. This means that the UCAR wetPf 2 water vapor profiles below $2 \mathrm{~km}$ altitude are heavily weighted by the $a$ priori water vapor. We used UCAR NearReal-Time (NRT) COSMIC-2 wetPf2 in this study where the Global Forecasting System (GFS) of NOAA National Centers for Environmental Prediction (NCEP) six-hour forecasts are used as the a priori.
On the other hand, NOAA/STAR independently developed a COSMIC-2 1DVAR retrieval algorithm to ensure the 1DVAR water vapor retrievals are using the information primarily from the refractivity instead of from the $a$ priori. The NOAA/STAR COSMIC-2 wetPrf data are available at ftp://ftp.star.nesdis.noaa.gov/pub/smcd/scda/GNSSRO/ COSMIC2/wetPrf/. In the 1DVAR algorithm for NOAA/ STAR wetPrf, the background error covariance and observation error (measurement noise) covariance matrices are constructed with GFS gridded low-resolution reanalysis data and proportional to monthly variations of temperature, humidity, and refractivity in corresponding latitude bins. The first guess (a priori) profiles in NOAA/STAR wetPrf are taken from GFS 6-hour forecast data interpolated to RO measurements' time and location to separate the pressure, temperature, and moisture contributions to the refractivity. Table 2 lists the difference between NOAA/STAR wetPrf and UCAR wetPf2 1DVAR retrieval algorithms. In NOAA/STAR 1DVAR, a very tight retrieval constraint is used to constrain the residual refractivity (between refractivity computed from the final temperature and moisture minus the observed refractivity) to be within the known observation errors (Ho et al. 2022). In the implementation of NOAA/STAR wetPrf, the residual refractivity threshold is set as $0.1 \%$ of given RO-observed refractivity. If this is unreachable, then the threshold is relaxed to $0.5 \%$. The most probable outputs are that the optimal estimator converges with residual $<0.1 \%$, or it does not converge even with a relaxed $0.5 \%$ threshold. Such criteria ensure that the 1DVAR retrievals are mainly contributed from the refractivity but

Table 1 . Temperature/humidity profile data for the COSMIC-2 used in the inter-comparison with RS41 or RS92 radiosonde measurements.

\begin{tabular}{ccc}
\hline Data Set Name & Provided by & Time Coverage \\
\hline UCAR-wetPf2 & UCAR & $2019 / 10 / 01$ to $2020 / 04 / 30$ \\
NOAA/STAR wetPrf & NOAA/STAR & $2019 / 10 / 01$ to $2020 / 04 / 30$ \\
\hline
\end{tabular}

Table 2. Comparison between NOAA/STAR wetPrf and UCAR wetPf2 1DVAR retrieval algorithms. ECMWF stands for European Centre for Medium-Range Weather Forecasts.

\begin{tabular}{c|cc}
\hline & NOAA/STAR wetPrf 1DVAR & UCAR NRT wetPf2 1DVAR (Wee 2018) \\
\hline Observation Error Covariance & $\begin{array}{c}\text { Scaled monthly variability of refractivity from } \\
\text { GFS reanalysis data }\end{array}$ & $\begin{array}{c}\text { Statistical variability of bending angle (estimated } \\
\text { with 9-year period of RO data) }\end{array}$ \\
\hline Background Error Covariance & $\begin{array}{c}\text { Monthly variability of temperature and humidity } \\
\text { profiles from GFS reanalysis data }\end{array}$ & $\begin{array}{c}\text { Monthly variability of temperature, pressure, and } \\
\text { relative humidity from ECMWF data over 9 years }\end{array}$ \\
\hline $\begin{array}{c}\text { Observation and Background Error Covariance } \\
\text { Matrix (ECM) Resolution and Construction }\end{array}$ & $\begin{array}{c}\text { Five latitude bins; Monthly; Precomputed on } \\
\text { fixed levels }\end{array}$ & $\begin{array}{c}10^{\circ} \times 10^{\circ} \text { Latitude/Longitude bins; Monthly; Precom- } \\
\text { puted on fixed levels }\end{array}$ \\
\hline Input to the algorithm & Refractivity & $\begin{array}{c}\text { Bending angle processed with variational regulation } \\
\text { of Abel transform }\end{array}$ \\
\hline $\begin{array}{c}\text { Initialization a priori (first guess) model and } \\
\text { control }\end{array}$ & $\begin{array}{c}\text { Global Forecasting System (GFS) 6-hour fore- } \\
\text { cast; Tight constraints on residual refractivity }\end{array}$ & Global Forecasting System (GFS) 6-hour forecast \\
\hline
\end{tabular}


not $a$ priori. The difference of the constraints on the information from the a priori model between the UCAR wetPf2 and NOAA/STAR wetPrf model can directly impact the retrieved data products in terms of temperature and humidity biases uncertainties. The NOAA/STAR 1DVAR retrieval algorithm is detailed in Ho et al. (2022).

The differences in the COSMIC-2 1DVAR retrieval algorithms are expected to exemplify themselves in the temperature and humidity differences over certain height regions. In this regard, using RAOB data can help evaluate the differences in the temperature and humidity data between COSMIC-2 retrievals from UCAR and NOAA/STAR. In this study, the temperature and humidity data from UCAR wetPf 2 and NOAA/STAR wetPrf COSMIC-2 retrievals are compared with RS41 and RS92 RAOB data to evaluate the uncertainty in the COSMIC-2 retrievals and the quality of RAOB data. The COSMIC-2 wet profile data contain latitude and longitude of the RO perigee point, temperature, pressure, specific humidity profile, and mean sea level height. The profile data are interpolated to 100-meter height intervals. The UCAR wetPf 2 data have been available in near real-time since 1 October 2019. This paper evaluates UCAR and NOAA/STAR COSMIC-2 wetPf2 data from 1 October 2019 to 30 April 2020, by comparing RS41 and RS92 RAOB data.

\subsection{Collocation and Data Analysis Method}

In the COSMIC-2 retrievals versus RAOB inter-comparison study, the data associated with the COSMIC-2 RO soundings and the RAOB measurements must be screened and collocated. In this study, collocated COSMIC-2 retrievals and RS41 or RS92 RAOB data within $150 \mathrm{~km}$ and 2 hours in locations and time are collected equatorward within $48^{\circ}$ latitude. The COSMIC- 2 geo-location is defined at the longitude/latitude of the perigee point at the occultation point. For COSMIC-2, RO profiles with attributes flags 'bad' $=1$, 'L2P' $=1$ are all screened out to ensure consistency in the RO data quality (personal communication with CDAAC). The 'bad' flag indicates that the COSMIC-2 retrievals are expected to be of bad quality and should be excluded in the analysis. The 'L2P' flag indicates the rising COSMIC-2 occultations, which use GPS transmitters and the L2P carrier frequency. There was a bias in the processing (personal communication with CDAAC) of L2P data in the provisional version of COSMIC-2 data, and therefore COSMIC-2 data with the 'L2P' flag were excluded in our analysis. This study's COSMIC-2 and RAOB data are collected over 7 months from October 2019 to April 2020. In total, about 2600 closely collocated COSMIC-2 and RS41 pairs and about 1200 collocated COSMIC-2 and RS92 pairs are collected for this study. During the earlier post-launch time of COSMIC-2, when the satellites in the COSMIC-2 constellation were in the process of settling down to the final orbital altitude and being homogeneously distributed, there are rare chances that the profiles observed by two COSMIC-2 satellites can meet the colocation criteria and match with the same RAOB. In our analysis, we don't differentiate among the six satellites of the COSMIC-2 constellation. The profiles observed by two COSMIC-2 satellites are treated as two independent matched profiles with RAOB and are equally evaluated in the bias and uncertainty analysis.

We use the hydrostatic equation to convert the RAOB pressure level to the geometric height. Then we interpolate the COSMIC-2 temperature data to the radiosondes' geometric height at $8,9.7,11,12.5,14.25,16.5,17.8,20,26.4$, and $30 \mathrm{~km}$ the RO versus RAOB temperature bias analysis, which is consistent with the mandatory levels of RAOB. For the RO versus RAOB humidity data comparison, the sampling interval is $0.6 \mathrm{~km}$ over the height region of interest below $8.4 \mathrm{~km}$. The spatial resolution chosen in this paper is twice higher than the mandatory levels of RAOB in this region. Both $\mathrm{RO}$ and $\mathrm{RAOB}$ humidity data are resampled to these fixed levels for comparison. Using this approach, we maintained high spatial resolution below $8.4 \mathrm{~km}$ and accounted for more RAOB data for comparison.

The mean temperature and humidity differences between COSMIC- 2 retrievals and the corresponding RS41 or RS92 pairs at the same height level $i$ are computed using the equation

$$
\Delta Y(i)=\frac{1}{n} \times \sum_{j=1}^{n}\left\{Y_{R O}(i, j)-Y_{R A O B}(i, j)\right\}
$$

$j$ is the index for all the matched pairs collected at all RS41 or RS92 stations. The RO versus RAOB temperature and humidity difference data are also used to compute the uncertainty (standard deviation) of the mean difference at the height level of interest.

\section{COMPARISON RESULTS}

\subsection{Overall Comparison of COSMIC-2 Temperature and Humidity Retrievals with RS41 and RS92 RAOB Measurements}

The humidity and temperature profiles processed by UCAR and NOAA/STAR COSMIC-2 1DVAR retrieval algorithms are compared with collocated RS41 and RS92 RAOB observations. The temperature profile comparisons are focused on the troposphere and lower stratosphere regions, i.e., height $>8 \mathrm{~km}$, where the amount of water vapor is negligible. The evaluation of humidity data quality is focused on the region with a height below $8 \mathrm{~km}$.

Figures $3 \mathrm{a}$ and $\mathrm{b}$ show the height-dependent mean temperature biases $[\mu(\Delta T)]$ and associated uncertainties $[\sigma(\Delta T)]$ of UCAR and NOAA/STAR COSMIC-2 temperate 
(a) RO - Radiosonde (RS41)

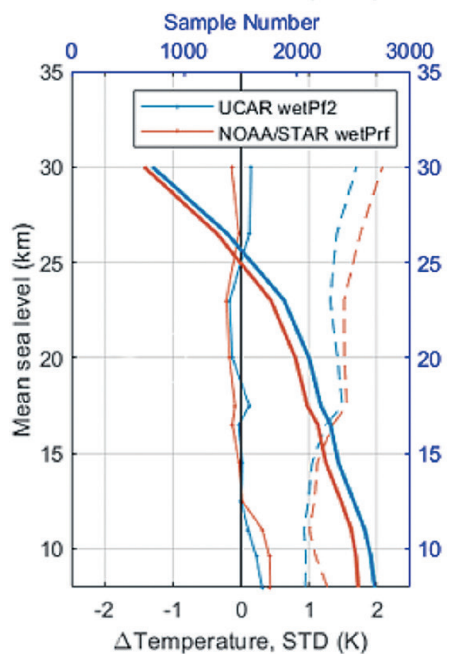

(c) RO - Radiosonde (RS41)

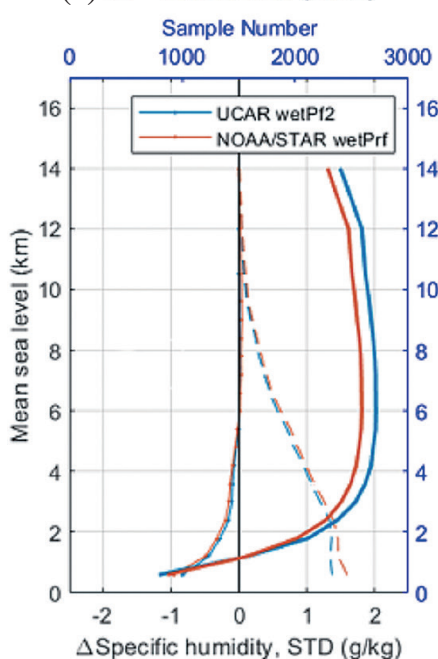

(b) RO - Radiosonde (RS92)

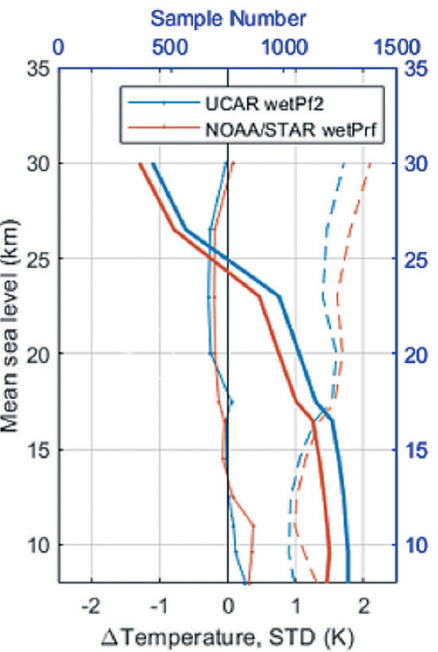

(d) RO - Radiosonde (RS92)

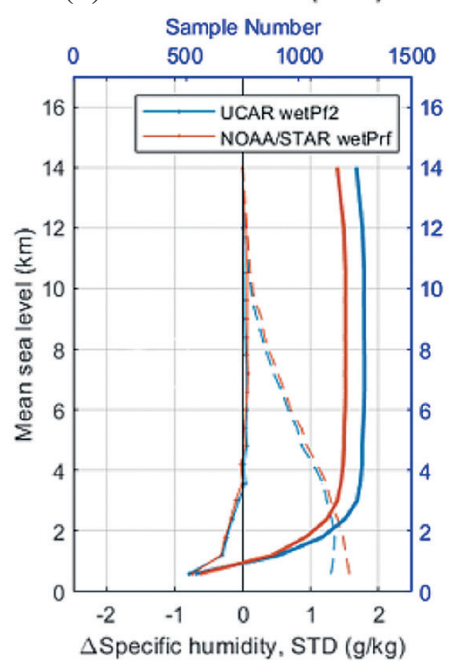

Fig. 3. (a) (b) Biases (dot lines) and uncertainties (dash lines) of COSMIC-2 temperature profiles retrieved by UCAR wetPf2 and NOAA/STAR wetPrf algorithms in comparison with (a) RS41 and (b) RS92 RAOB data. (c) (d) Biases (dot lines) and uncertainties (dash lines) of UCAR and NOAA/ STAR COSMIC-2 humidity retrievals in comparison with (c) RS41 and (d) RS92 RAOB data. The height variation of the number of samples used in the corresponding bias analysis is shown as solid lines in each panel.

retrievals relative to RS41 and RS92 RAOB observations, respectively. The height-varying number of collocated ROretrievals and $\mathrm{RAOB}$ used to derive the bias statistics are also shown in each panel. The number of matched samples between RS41 and UCAR or NOAA/STAR COSMIC-2 retrievals is almost double of those matched cases with RS92. At height $=8 \mathrm{~km}$, the number of matched samples are about at the maximum with $N_{U C A R-R S 41}=2684, N_{\text {NOAASTAR-RS } 41}=2539$, $N_{U C A R-R S 92}=1283$, and $N_{\text {NOAASTAR-RS92 }}=1189$. The number of RAOB-matched UCAR COSMIC-2 retrievals is slightly more than those matched with NOAA/STAR retrievals.

To quantify the temperature bias differences over different height regions, Tables 3 and 4 show the mean temperature bias difference $[\mu(\Delta T)]$ over three height regions, e.g., 8 - 11, 12.5 - 16.5, and $17.8-26.4 \mathrm{~km}$, which are derived from the comparison of two retrievals with RS41 and RS92 RAOB observations shown in Figs. 3a and b, respectively.

The overall consistency of the temperature biases derived from two COSMIC-2 1DVAR retrievals can be seen in several aspects. Compared with RS41 RAOB, both and $\Delta T_{\text {STAR-RS41 }}$ in Fig. 3a show small negative biases over the height region between 17.8 and $26.4 \mathrm{~km}$. Similarly, both $\Delta T_{\text {UCAR-RS92 }}$ and $\Delta T_{\text {STAR-RS92 }}$ in Fig. $3 \mathrm{~b}$ show slightly larger negative biases over the same height region. Quantitatively, the mean biases of this height region in Tables 3 and 4 show that $\mu\left(\Delta T_{\text {UCAR-RS92 }}\right)$ is lower than $\mu\left(\Delta T_{\text {UCAR-RS41 }}\right)$ by $0.17 \mathrm{~K}$ while $\mu\left(\Delta T_{\text {STAR-RS92 }}\right)$ is lower than $\mu\left(\Delta T_{\text {STAR-RS41 }}\right)$ by $0.05 \mathrm{~K}$. Using UCAR or NOAA/STAR COSMIC-2 temperature as the reference, this indicates that the RS92 RAOB has a warm bias of around $0.1 \mathrm{~K}$ over the height region between 17.8 and 
Table 3. Mean temperature biases (uncertainties) $(\mathrm{K})$ and mean humidity biases (uncertainties) $\left(\mathrm{g} \mathrm{kg}^{-1}\right)$ between two RO retrievals and RS41 RAOB observations over different height regions.

\begin{tabular}{|c|c|c|c|c|c|}
\hline $\begin{array}{c}\text { COSMIC-2 } \\
\text { Retrieval }\end{array}$ & $\begin{array}{c}\mu(\Delta T)[\sigma(\Delta T)](\mathrm{K}) \\
(8-11 \mathrm{~km})\end{array}$ & $\begin{array}{c}\mu(\Delta T)[\sigma(\Delta T)](\mathrm{K}) \\
(12.5-16.5 \mathrm{~km}) \\
\end{array}$ & $\begin{array}{c}\mu(\Delta T)[\sigma(\Delta T)](\mathrm{K}) \\
(17.8-26.4 \mathrm{~km}) \\
\end{array}$ & $\begin{array}{c}\mu(\Delta H)[\sigma(\Delta H)]\left(\mathrm{g} \mathrm{kg}^{-1}\right) \\
(\text { below } 4.2 \mathrm{~km})\end{array}$ & $\begin{array}{c}\mu(\Delta H)[\sigma(\Delta H)]\left(\mathrm{g} \mathrm{kg}^{-1}\right) \\
(4.8-8.4 \mathrm{~km})\end{array}$ \\
\hline UCAR wetPf2 & $0.22(0.95)$ & $0.00(1.10)$ & $-0.01(1.42)$ & $-0.28(1.24)$ & $0.01(0.50)$ \\
\hline STAR wetPrf & $0.39(1.13)$ & $-0.04(1.19)$ & $-0.12(1.59)$ & $-0.33(1.33)$ & $0.01(0.54)$ \\
\hline
\end{tabular}

Table 4. Mean temperature biases (uncertainties) $(\mathrm{K})$ and mean humidity biases (uncertainties) $\left(\mathrm{g} \mathrm{kg}^{-1}\right)$ between two RO retrievals and RS92 RAOB observations over different height regions.

\begin{tabular}{|c|c|c|c|c|c|}
\hline $\begin{array}{c}\text { COSMIC-2 } \\
\text { Retrieval }\end{array}$ & $\begin{array}{c}\mu(\Delta T)[\sigma(\Delta T)](\mathrm{K}) \\
(8-11 \mathrm{~km})\end{array}$ & $\begin{array}{c}\mu(\Delta T)[\sigma(\Delta T)](\mathrm{K}) \\
(12.5-16.5 \mathrm{~km})\end{array}$ & $\begin{array}{c}\mu(\Delta T)[\sigma(\Delta T)](\mathrm{K}) \\
(17.8-26.4 \mathrm{~km})\end{array}$ & $\begin{array}{c}\mu(\Delta H)[\sigma(\Delta H)]\left(\mathrm{g} \mathrm{kg}^{-1}\right) \\
(\text { below } 4.2 \mathrm{~km})\end{array}$ & $\begin{array}{c}\mu(\Delta H)[\sigma(\Delta H)]\left(\mathrm{g} \mathrm{kg}^{-1}\right) \\
(4.8-8.4 \mathrm{~km})\end{array}$ \\
\hline UCAR wetPf2 & $0.16(0.93)$ & $-0.01(1.09)$ & $-0.18(1.50)$ & $-0.21(1.25)$ & $0.05(0.58)$ \\
\hline STAR wetPrf & $0.35(1.14)$ & $-0.01(1.18)$ & $-0.17(1.68)$ & $-0.23(1.37)$ & $0.06(0.63)$ \\
\hline
\end{tabular}

$26.4 \mathrm{~km}$ in comparison with RS41 RAOB. This is consistent with the previous analysis of the COSMIC RO and RAOB data (Ho et al. 2010b), suggesting that the temperature biases are mainly in the radiosonde data. Ho et al. (2020b) showed that RS92 has warm stratospheric biases, and RS41 has smaller warm biases than RS92.

Over the height region between 12.5 and $17 \mathrm{~km}$, the RS41 and RS92 RAOBs match both UCAR and NOAA/ STAR COSMIC-2 temperature profiles very well with almost $0 \mathrm{~K}$ biases. The major temperature difference between COSMIC-2 retrievals and RAOB occurs over the height region between 8 and $11 \mathrm{~km}$, as shown in Figs. 3a and b. Over this height region, the mean biases $\mu\left(\Delta T_{U C A R-R S 41}\right)$ and $\mu\left(\Delta T_{U C A R-R S 92}\right)$ are both positive with the values of 0.22 and $0.16 \mathrm{~K}$, respectively, while $\mu\left(\Delta T_{\text {STAR-RS41 }}\right)$ and $\mu\left(\Delta T_{\text {STAR-RS92 }}\right)$ are positive and around 0.39 and $0.35 \mathrm{~K}$, respectively. There is a net difference of $\sim 0.2 \mathrm{~K}$ between UCAR and NOAA/ STAR temperature retrievals over the 8 to $11 \mathrm{~km}$ height range, with warmer NOAA/STAR temperature retrieval.

In terms of uncertainties, the $\sigma(\Delta T)$ of UCAR wetPf2 versus RS41 or RS92 RAOB is, in general, smaller than $\sigma(\Delta T)$ of NOAA/STAR wetPrf versus RS41 or RS92 RAOB with the difference in $\sigma(\Delta T)$ being minimum around height $=17.8 \mathrm{~km}$ and reaching the maximum of $0.2 \mathrm{~K}$ and $0.3 \mathrm{~K}$ at 8 and $30 \mathrm{~km}$, respectively. Such difference in the biases over $8-11 \mathrm{~km}$ and uncertainties between UCAR and NOAA/STAR temperature retrievals can be due to the differences in the 1DVAR retrieval model implementation such as different background and observation error covariance model used, weighting on the a priori model, and background and observation ECM construction.

The height-varying humidity difference between COSMIC-2 1DVAR retrievals and RS41 or RS92 RAOBs are shown in Figs. 3c and d, respectively. Tables 3 and 4 show the mean humidity biases (uncertainties) over two height ranges between COSMIC-2 retrievals and RS41 or RS92
RAOBs, respectively.

The humidity differences between two COSMIC-2 retrievals and RAOBs such as $\Delta H_{U C A R-R S 41}, \Delta H_{S T A R-R S 41}$, $\Delta H_{\text {UCAR-RS92 }}$, and $\Delta H_{\text {STAR-RS92 }}$ are all relatively small above $4 \mathrm{~km}$ (see Tables 3 and 4). This suggests the overall consistencies between COSMIC-2 retrievals and RAOBs, which indicates the consistency between the UCAR and NOAA/ STAR COSMIC-2 humidity retrievals compared with RS41 and RS92 RAOBs over this height region. Below $4 \mathrm{~km}$, UCAR and NOAA/STAR COSMIC-2 humidity retrievals deviate from RS41 or RS92 RAOB observations with increasing negative humidity biases approaching the surface. This may indicate systematic wet biases in the RAOB data relative to the near-surface RO humidity retrievals. Such near-surface negative humidity bias between COMSIC-2 and RAOBs is consistent with the previous results from comparing COSMIC-1 and RAOB observations (Wang et al. 2013). This may indicate the negative refractivity biases owing to super-refraction (see section 5.4 of Ho et al. 2020b). On the other hand, the UCAR and NOAA/STAR COSMIC-2 humidity retrievals over the height range 0 $4.2 \mathrm{~km}$ are quite consistent, as can be seen from the overall humidity difference matching in Figs. $3 c$ and $d$ and the mean humidity difference values in Tables 3 and 4 . The difference of the mean humidity bias between RS41 and RS92 over 0 - $4.2 \mathrm{~km}$ is about 0.07 and $0.10 \mathrm{~g} \mathrm{~kg}^{-1}$ from UCAR and NOAA/STAR retrievals, respectively, indicating slight dry bias of RS92 relative to RS41 over this height range.

The above analysis of overall temperature and humidity biases between two COSMIC-2 retrievals and RS41/ RS92 observations shows the differences between UCAR and NOAA/STAR COSMIC-2 1DVAR retrieval algorithms are manifested mainly in the temperature bias differences over the height range $8-12.5 \mathrm{~km}$. The humidity retrievals of these two algorithms generally matched quite well over the height region of interest. 


\subsection{Variation of Temperature and Humidity Biases Between RO and RAOB over Day and Nighttime}

\subsubsection{Day and Nighttime Temperature Bias Comparison}

To study the dependence of the temperature and humidity biases of COSMIC- 2 retrievals versus RAOB observations on the solar zenith angle, the bias data are processed according to three SZA groups such as daytime (SZA < $\left.80^{\circ}\right)$, dusk/dawn $\left(80^{\circ}<\mathrm{SZA}<100^{\circ}\right)$, and nighttime (SZA > $100^{\circ}$ ). Figure 4 shows the height-dependent temperature biases over three SZA zones derived from the comparisons of UCAR and NOAA/STAR COSMIC-2 retrievals with RS41 (Figs. 4a - b) or RS92 (Figs. 4c - d) RAOB observations. Figure 5 shows the mean temperature biases and uncertainties (also listed in Tables 5 and 6) over three height regions (8 - 11, 12.5 - 16.5, and 17.8 - $26.4 \mathrm{~km}$ ) and three SZA zones from the data shown in Fig. 4. The number of COSMIC-2 and RAOB collocations over the dusk/dawn zone is relatively small compared to daytime and nighttime zones. In this analysis, we focus on the comparison over the day and night SZA zones.

As shown in Figs. $4 \mathrm{a}-\mathrm{b}$, the daytime biases $\Delta T_{U C A R-}$ ${ }_{R S 41}$ and $\Delta T_{\text {STAR-RS41 }}$ over the height from 17.8 to $26.4 \mathrm{~km}$ derived from COSMIC-2 retrievals relative to RS41 RAOB comparison are slightly higher than the corresponding nighttime biases. Quantitatively, the mean daytime biases $\mu\left(\Delta T_{\text {UCAR-RS41 }}\right)$ and $\mu\left(\Delta T_{\text {STAR-RS41 }}\right)$ over $17.8-26.4 \mathrm{~km}$ (Figs. 5a - b and Table 5) are higher than the nighttime biases by 0.13 and $0.17 \mathrm{~K}$, respectively. Since the daytime biases of $\Delta T_{U C A R-R S 41}$ and $\Delta T_{\text {STAR-RS41 }}$ are relatively small over this region, the comparison suggests that there are $\sim 0.1 \mathrm{~K}$ warm biases in the RS41 nighttime measurements, which can come from the temperature correction scheme implemented for RS41.

From Figs. $4 \mathrm{c}-\mathrm{d}$ and Table 6, the daytime COSMIC-2 versus RS92 biases $\Delta T_{U C A R-R S 92}$ and $\Delta T_{\text {STAR-RS92 }}$ are on average lower by $\sim 0.24$ and $0.15 \mathrm{~K}$, respectively, than the corresponding night time biases over the height region from 17.8 to $26.4 \mathrm{~km}$. This indicates that the cause of the overall 0.15 - 0.24 K warm bias of RS92 RAOB measurements from 17.8 to $26.4 \mathrm{~km}$ (shown in Fig. 3b) is due to the warm daytime bias of RS92 which could be traceable to the calibration of the daytime temperature for the RS92 sensor (Dirksen et al. 2014). The radiation-induced error in radiosonde temperature measurements is a significant issue with radiosonde observations in the upper troposphere and lower stratosphere. While rising in altitude, the radiosonde can experience less efficient ventilation due to the reduced air density around the radiosonde at high altitudes. Therefore, the solar radiation on (a)

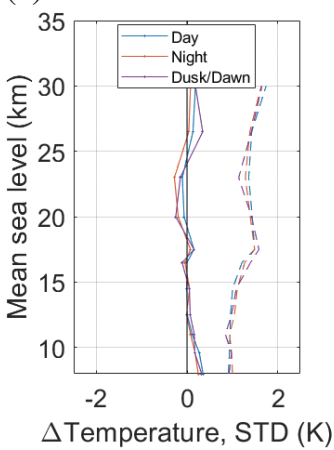

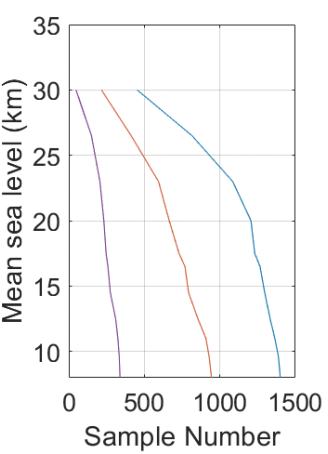

(b)

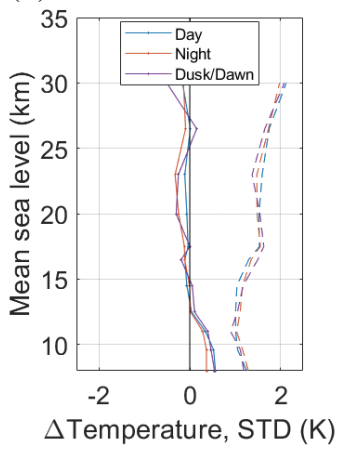

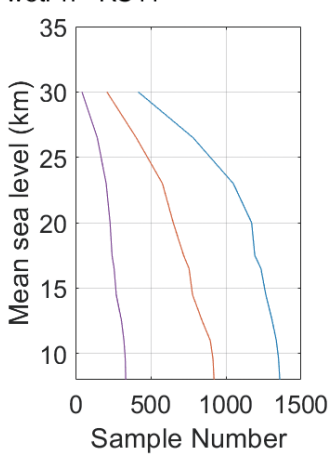

(d)
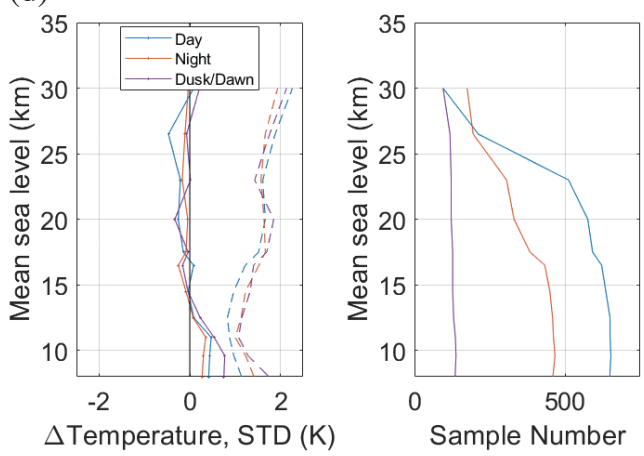

Fig. 4. Left panels in (a) - (d): Height-dependent temperature biases and uncertainties (K) of (a) UCAR wetPf2 versus RS41, (b) NOAA/STAR wetPrf versus RS41, (c) UCAR wetPf2 versus RS92, and (d) NOAA/STAR wetPrf versus RS92 RAOB observations in three SZA zones of daytime $\left(\mathrm{SZA}<80^{\circ}\right)$, nighttime $\left(\mathrm{SZA}>100^{\circ}\right)$, and dusk/dawn $\left(80^{\circ}<\mathrm{SZA}<100^{\circ}\right)$. Right panels in (a) - (d) show the height-varying sample number corresponding to the collocated cases in the three SZA zones shown in the left panels. 

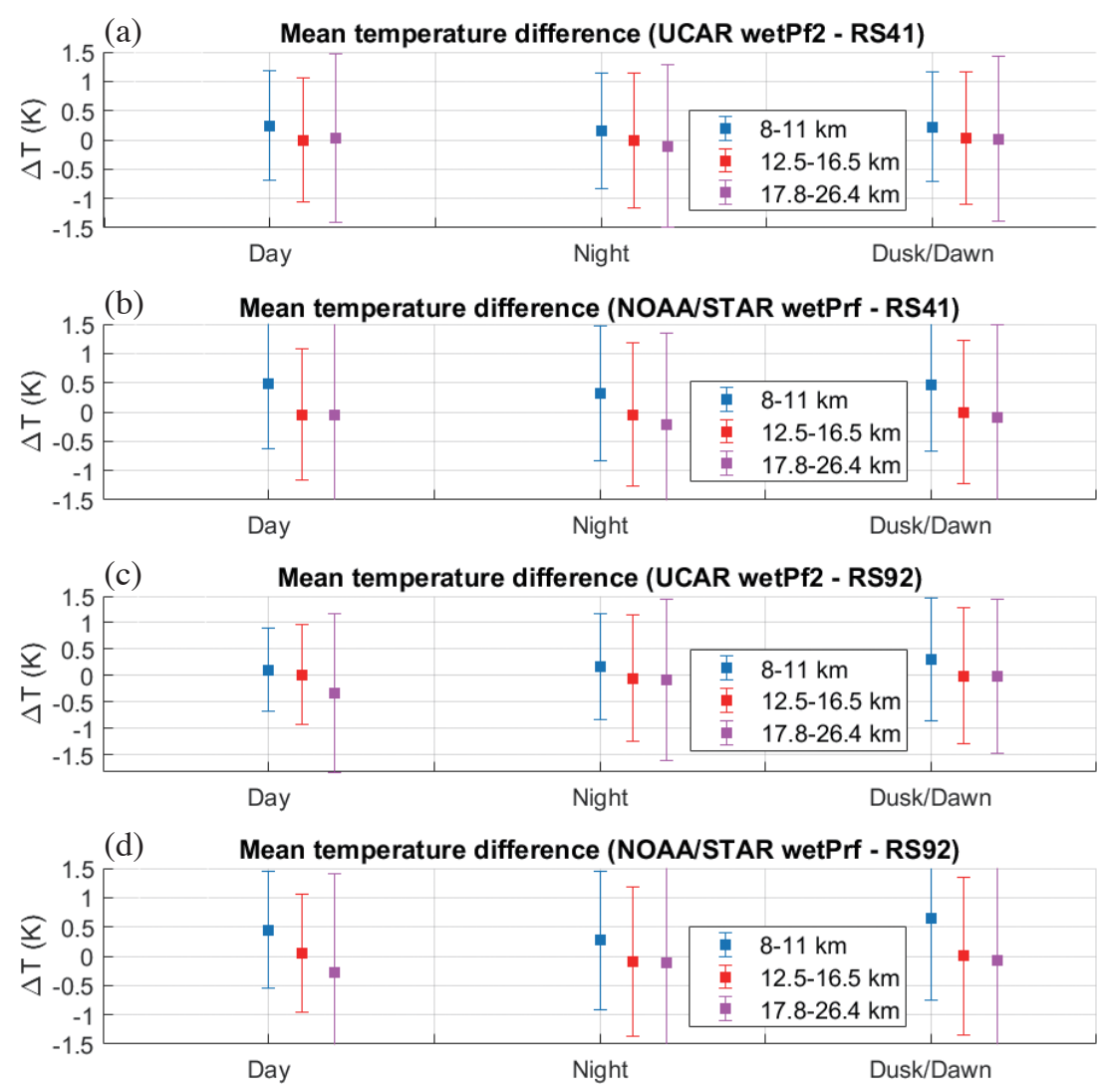

Fig. 5. Mean temperature biases (K) of (a) UCAR wetPf2 versus RS41, (b) NOAA/STAR wetPrf versus RS41, (c) UCAR wetPf2 versus RS92, and (d) NOAA/STAR wetPrf versus RS92 RAOB observations in the zones of daytime $\left(\mathrm{SZA}<80^{\circ}\right)$, nighttime $\left(\mathrm{SZA}>100^{\circ}\right)$, and dusk $/$ dawn $\left(80^{\circ}<\right.$ $\mathrm{SZA}<100^{\circ}$ ) over three height regions in the upper troposphere and lower stratosphere.

Table 5. Mean temperature biases (uncertainties) (K) between RO retrievals and RS41 RAOB observations over three height regions and three SZA zones.

\begin{tabular}{c|cccc}
\hline Height Range & RO Retrievals & Day & Night & Dusk/Dawn \\
\hline \multirow{2}{*}{$8-11 \mathrm{~km}$} & UCAR wetPf2 & $0.25(0.93)$ & $0.15(0.98)$ & $0.22(0.93)$ \\
& STAR wetPrf & $0.43(1.11)$ & $0.31(1.17)$ & $0.39(1.11)$ \\
\hline \multirow{2}{*}{$12.5-16.5 \mathrm{~km}$} & UCAR wetPf2 & $-0.00(1.06)$ & $-0.02(1.15)$ & $0.03(1.14)$ \\
& STAR wetPrf & $-0.04(1.15)$ & $-0.06(1.24)$ & $-0.02(1.25)$ \\
\hline \multirow{2}{*}{$17.8-26.4 \mathrm{~km}$} & UCAR wetPf2 & $0.03(1.43)$ & $-0.10(1.38)$ & $0.02(1.40)$ \\
& STAR wetPrf & $-0.08(1.61)$ & $-0.25(1.56)$ & $-0.05(1.58)$ \\
\hline
\end{tabular}

Table 6. Mean temperature biases (uncertainties) (K) between RO retrievals and RS92 RAOB observations over three height regions and three SZA zones.

\begin{tabular}{c|cccc}
\hline Height Range & RO Retrievals & Day & Night & Dusk/Dawn \\
\hline \multirow{2}{*}{$8-11 \mathrm{~km}$} & UCAR wetPf2 & $0.11(0.79)$ & $0.16(1.00)$ & $0.30(1.16)$ \\
& STAR wetPrf & $0.37(0.98)$ & $0.22(1.21)$ & $0.54(1.42)$ \\
\hline \multirow{2}{*}{$12.5-16.5 \mathrm{~km}$} & UCAR wetPf2 & $0.02(0.94)$ & $-0.06(1.19)$ & $-0.01(1.29)$ \\
& STAR wetPrf & $0.04(1.01)$ & $-0.09(1.28)$ & $-0.02(1.41)$ \\
\hline \multirow{2}{*}{$17.8-26.4 \mathrm{~km}$} & UCAR wetPf2 & $-0.32(1.50)$ & $-0.08(1.52)$ & $-0.02(1.46)$ \\
& STAR wetPrf & $-0.28(1.68)$ & $-0.13(1.70)$ & $-0.01(1.63)$ \\
\hline
\end{tabular}


the radiosonde sensor can cause its temperature to be typically warm biased during the daytime.

Over the height region of 12.5 to $16.5 \mathrm{~km}$, the bias difference between day and nighttime is relatively small, as shown in Fig. 5 and Tables 5 - 6, which suggests the consistency among UCAR and NOAA/STAR temperature retrievals, and RS41 and RS92 RAOB measurements over this height range.

Over the height range $8-12.5 \mathrm{~km}$, the $\Delta T_{U C A R-R S 41}$ and $\Delta T_{U C A R-R S 92}$ of day time and nighttime are aligned well, as shown in Figs. 4a and c and quantitatively in Tables 5 and 6. The corresponding mean day-night temperature bias difference of both $\Delta T_{U C A R-R S 41}$ and $\Delta T_{U C A R-R S 92}$ from 8 to $11 \mathrm{~km}$ is less than $0.1 \mathrm{~K}$. This indicates that the day-night difference for RS41 and RS92 measurements is relatively small over this height region. On the other hand, the mean biases of NOAA/STAR COSMIC-2 temperature retrievals relative to RS41 and RS92 from 8 to $11 \mathrm{~km}$ are higher by $0.1-0.2 \mathrm{~K}$ than those of the UCAR temperature retrievals. This suggests that the COSMIC-2 1DVAR temperature retrieval algorithms' uncertainty and the difference can be the leading cause of the temperature bias difference over this height region.

In terms of uncertainties, Fig. 5 shows a relatively larger temperature bias uncertainty over the $17.8-26.4 \mathrm{~km}$ height region than the other two regions. This is due to the uncertainty bump above $17.8 \mathrm{~km}$, as shown in Fig. 4. This uncertainty bump is due to the transition from a geometric opticsbased algorithm to a wave-optics algorithm in retrieving RO bending angle from excess phase data. Due to the multi-path propagation of GNSS signals in the troposphere, which is affected by refractions through the atmosphere with moisture, pressure, and temperature profile variations, a wave-optics algorithm is used to retrieve bending angles below $\sim 18 \mathrm{~km}$. Such transition at $\sim 18 \mathrm{~km}$ in the bending angle retrieval algorithm produces larger uncertainty in COSMIC-2 bending angle data over height region around $18 \mathrm{~km}$ relative to other height regions above $8 \mathrm{~km}$. The bump around $18 \mathrm{~km}$ in the COSMIC-2 refractivity uncertainty shown in Ho et al. 2020b is of similar shape as the bump of temperature uncertainty shown in Fig. 4. This suggests that the temperature comparison between COSMIC-2 and RAOB captures the uncertainty in the COSMIC-2 bending angle retrievals.

Figures $4 \mathrm{a}$ and $\mathrm{b}$ show that the standard deviations of $\Delta T_{U C A R-R S 41}$ and $\Delta T_{\text {STAR-RS41 }}$ over daytime, nighttime, and dusk/dawn are relatively consistent for the RS41 versus UCAR or NOAA/STAR temperature retrieval comparison. The standard deviation $\sigma\left(\Delta T_{\text {STAR-RS41 }}\right)$ is more significant than $\sigma\left(\Delta T_{U C A R-R S 41}\right)$ by $0.2-0.3 \mathrm{~K}$ at height $=8$ and 30 $\mathrm{km}$, and they are matched at $17.8 \mathrm{~km}$. On the other hand, Figs. $4 \mathrm{c}$ and $\mathrm{d}$ show that the standard deviations of both $\Delta T_{\text {UCAR-RS92 }}$ and $\Delta T_{\text {STAR-RS92 }}$ are different between over daytime and nighttime with the nighttime $\sigma\left(\Delta T_{\text {STAR-RS41 }}\right)$ and $\sigma\left(\Delta T_{\text {STAR-RS92 }}\right)$ being more significant for height below 17.8 $\mathrm{km}$. Similarly, $\sigma\left(\Delta T_{\text {STAR-RS41 }}\right)$ is larger than $\sigma\left(\Delta T_{U C A R-R S 41}\right)$ at 8 and $30 \mathrm{~km}$.

\subsubsection{Day and Nighttime Humidity Bias Comparison}

The radiosonde sensor measurement accuracy varies considerably in times and locations for different sensor types (e.g., Wang and Zhang 2008; Ho et al. 2010a; Sun et al. 2013). Various methods have been developed to correct known humidity observational errors for radiosonde through statistical approaches (Turner et al. 2003; Vömel et al. 2007), and laboratory or physical-based correction schemes (Leiterer et al. 1997; Wang et al. 2002). Such humidity corrections vary by day and night time and according to sensor types. Due to the lack of benchmark humidity references, it is still challenging to quantify the possible errors even after applying those humidity corrections. Consequently, the moisture climatology constructed using radiosonde measurements is still subject to significant uncertainty.

On the other hand, the humidity data retrieved from RO data using 1DVAR algorithms can have uncertainties due to the difference in constructing and implementing the IDVAR retrieval algorithms. This section compares the humidity data derived from collocated COSMIC-2 retrievals and RS41 or RS92 observations over daytime and nighttime. The variation of RO versus RAOB humidity biases over height and day/night are evaluated.

Figure 6 shows the analysis of the humidity biases between COSMIC-2 retrievals and RAOB observations according to daytime, dusk/dawn, and nighttime SZA zones. In particular, the height-dependent humidity biases over these three SZA zones are derived from the comparisons of UCAR and NOAA/STAR COSMIC-2 humidity retrievals with RS41 (Figs. 6a - b) or RS92 (Figs. 6c - d) RAOB observations. To quantify the humidity biases among various RAOB measurements, retrieval algorithms, and SZA zones, the mean humidity biases over two height regions (below $4.2 \mathrm{~km}$ and $4.8-8.4 \mathrm{~km}$ ) are calculated for each case in Fig. 6. The results are summarized in Fig. 7 and Tables 7 - 8 .

Over the height range below $4.2 \mathrm{~km}$, Figs. $6 \mathrm{a}$ - b show that the humidity biases between UCAR or NOAA/STAR COSMIC-2 humidity retrievals and RS41 RAOB are negative over three SZA zones. This can also be observed in Fig. 7 by comparing the mean daytime, nighttime, and dusk/dawn humidity biases below $4.2 \mathrm{~km}$ with those above $4.2 \mathrm{~km}$. These humidity biases all have a similar pattern of growing bias amplitude as approaching the lower altitude. These water vapor biases could be due to the COSMIC-2 negative refractivity biases resulting from the super-refraction condition for the RO signal in the moisture lower troposphere (see section 5.4 of Ho et al. 2020b). The mean day versus night humidity bias difference between COSMIC-2 retrievals and RS41 RAOB below $4.2 \mathrm{~km}$ are 

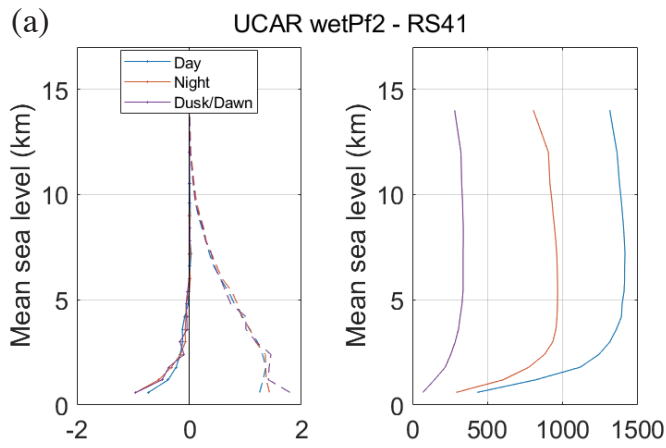

$\Delta$ Specific humidity, STD $(\mathrm{g} / \mathrm{kg}) \quad$ Sample Number

(c)
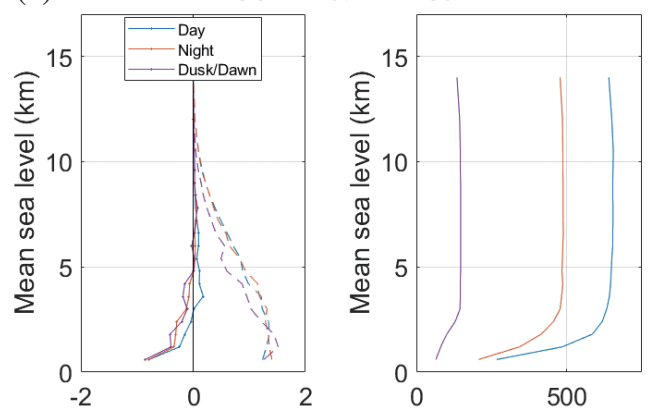

(b)

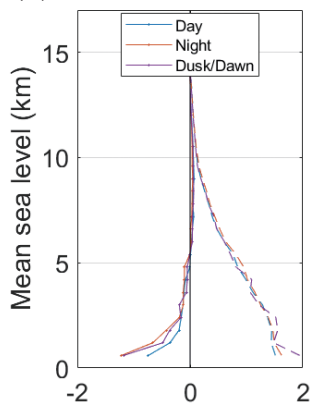

NOAA/STAR wetPrf - RS41

$\Delta$ Specific humidity, STD $(\mathrm{g} / \mathrm{kg})$

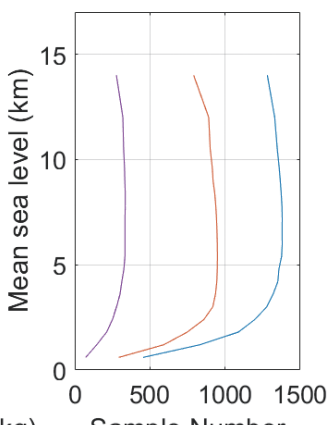

(d)

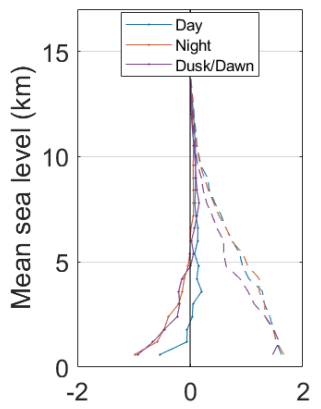

$\Delta$ Specific humidity, STD $(\mathrm{g} / \mathrm{kg})$

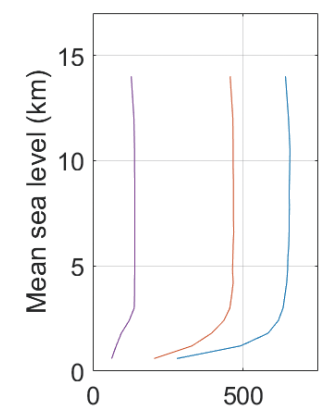

Sample Number

Fig. 6. Left panels in (a) - (d): Height-dependent humidity biases and uncertainties $\left(\mathrm{g} \mathrm{kg}^{-1}\right)$ of (a) UCAR wetPf2 versus RS41, (b) NOAA/STAR wetPrf versus RS41, (c) UCAR wetPf2 versus RS92, and (d) NOAA/STAR wetPrf versus RS92 RAOB observations in three SZA zones of daytime $\left(\mathrm{SZA}<80^{\circ}\right)$, nighttime $\left(\mathrm{SZA}>100^{\circ}\right)$, and dusk/dawn $\left(80^{\circ}<\mathrm{SZA}<100^{\circ}\right)$. Right panels in (a) - (d) show the height-varying sample number corresponding to the collocated cases in the three SZA zones shown in the left panels.
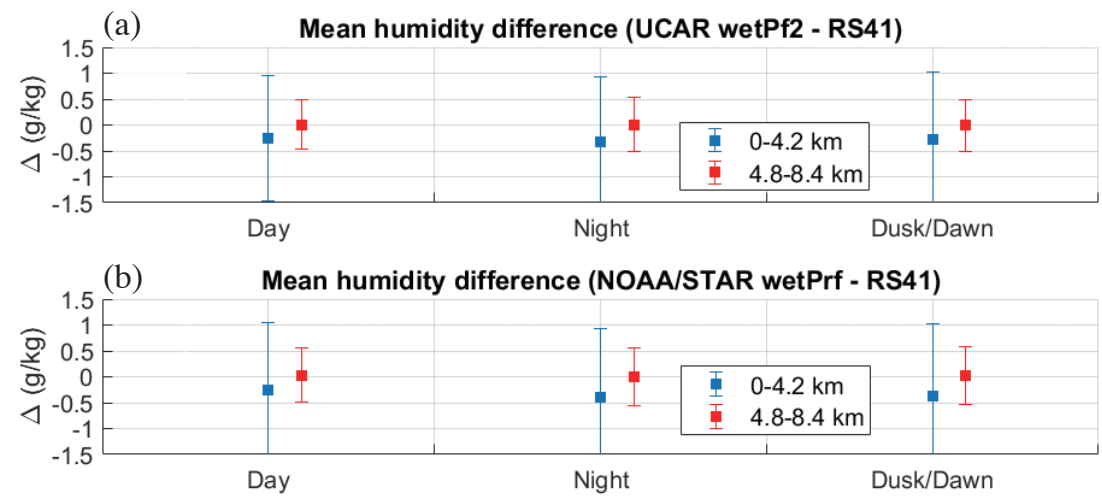

(c) Mean humidity difference (UCAR wetPf2 - RS92)
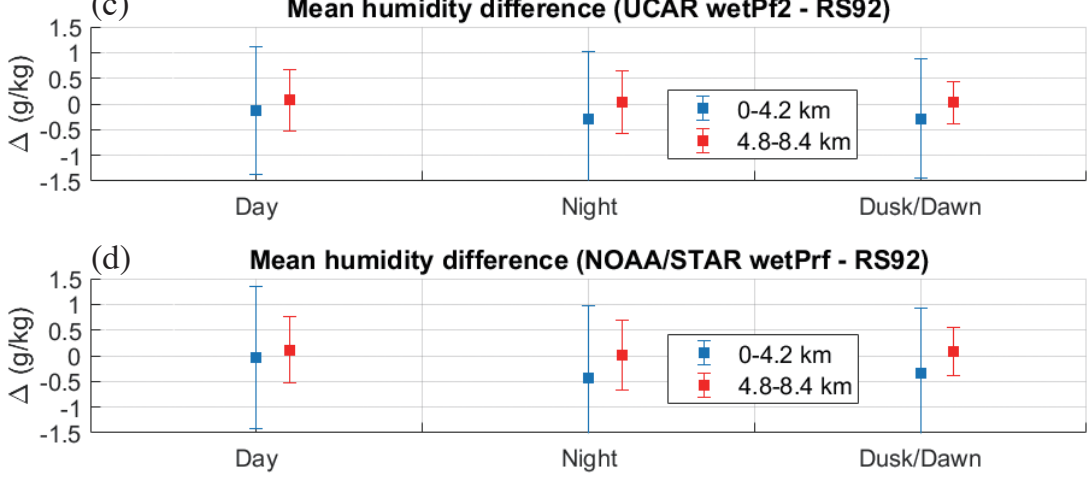

Fig. 7. Mean humidity biases ( $\mathrm{g} \mathrm{kg}^{-1}$ ) of (a) UCAR wetPf2 versus RS41, (b) NOAA/STAR wetPrf versus RS41, (c) UCAR wetPf2 versus RS92, and (d) NOAA/STAR wetPrf versus RS92 RAOB observations in the zones of day $\left(\mathrm{SZA}<80^{\circ}\right)$, night $\left(\mathrm{SZA}>100^{\circ}\right)$, and dusk $/$ dawn $\left(80^{\circ}<\mathrm{SZA}\right.$ $<100^{\circ}$ ) over two height regions. 
Table 7. Mean humidity biases (uncertainties) $\left(\mathrm{g} \mathrm{kg}^{-1}\right)$ between RO retrievals and RS41 RAOB observations over two height regions and three SZA zones.

\begin{tabular}{c|cccc}
\hline Height Range & RO Retrievals & Day & Night & Dusk/Dawn \\
\hline \multirow{2}{*}{ Below $4.2 \mathrm{~km}$} & UCAR wetPf2 & $-0.26(1.21)$ & $-0.32(1.24)$ & $-0.28(1.31)$ \\
& STAR wetPrf & $-0.28(1.31)$ & $-0.42(1.34)$ & $-0.36(1.36)$ \\
\hline \multirow{2}{*}{$4.8-8.4 \mathrm{~km}$} & UCAR wetPf2 & $0.01(0.48)$ & $0.01(0.52)$ & $-0.01(0.49)$ \\
& STAR wetPrf & $0.02(0.52)$ & $-0.00(0.56)$ & $0.00(0.54)$ \\
\hline
\end{tabular}

Table 8. Mean humidity biases (uncertainties) $\left(\mathrm{g} \mathrm{kg}^{-1}\right)$ between RO retrievals and RS92 RAOB observations over two height regions and three SZA zones.

\begin{tabular}{c|cccc}
\hline Height Range & RO Retrievals & Day & Night & Dusk/Dawn \\
\hline \multirow{2}{*}{ Below $4.2 \mathrm{~km}$} & UCAR wetPf2 & $-0.13(1.24)$ & $-0.30(1.32)$ & $-0.28(1.16)$ \\
& STAR wetPrf & $-0.08(1.37)$ & $-0.41(1.43)$ & $-0.35(1.18)$ \\
\hline \multirow{2}{*}{$4.8-8.4 \mathrm{~km}$} & UCAR wetPf2 & $0.07(0.60)$ & $0.04(0.61)$ & $0.03(0.41)$ \\
& STAR wetPrf & $0.09(0.64)$ & $0.00(0.68)$ & $0.06(0.48)$ \\
\hline
\end{tabular}

$\sim 0.06$ and $0.14 \mathrm{~g} \mathrm{~kg}^{-1}$ for $\mu\left(\Delta H_{\text {UCAR-RS41 }}\right)$ and $\mu\left(\Delta H_{\text {STAR-RS41 }}\right)$, respectively. This suggests that the daytime and nighttime biases of UCAR COSMIC-2 humidity versus RS41 RAOB are matched quite well below $4.2 \mathrm{~km}$, as shown in Fig. $6 \mathrm{a}$.

On the other hand, the day-night humidity bias difference can be identified below $4.2 \mathrm{~km}$ when comparing UCAR and NOAA/STAR retrievals with RS92 RAOBs, as shown in Figs. 6c - d and Table 8. Particularly, the mean daytime humidity biases $\mu\left(\Delta H_{\text {UCAR-RS92 }}\right)$ and $\mu\left(\Delta H_{\text {STAR-RS92 }}\right)$ below $4.2 \mathrm{~km}$ are higher by 0.17 and $0.33 \mathrm{~g} \mathrm{~kg}^{-1}$, respectively, than those of nighttime, with the daytime biases being closer to $0 \mathrm{~g} \mathrm{~kg}^{-1}$.

The mean nighttime biases below $4.2 \mathrm{~km}$ between UCAR or NOAA/STAR humidity and RS41 or RS92 data, i.e., $\mu\left(\Delta H_{\text {UCARISTAR-RS41 }}\right)$ versus $\mu\left(\Delta H_{\text {UCARISTAR-RS92 }}\right)$, are in the range of -0.3 to $-0.4 \mathrm{~g} \mathrm{~kg}^{-1}$. From Tables 7 and 8 , it can also be found that the mean humidity bias of RS41 versus UCAR or NOAA/STAR humidity at daytime is lower by 0.13 and $0.2 \mathrm{~g} \mathrm{~kg}^{-1}$, respectively, compared to those of RS92.

In summary, the humidity biases between UCAR or NOAA/STAR COSMIC-2 and RS41 or RS92 data are all consistently negative except the daytime humidity biases of RS92. The out-of-family daytime humidity bias of COSMIC-2 versus RS92 can be owing to the daytime correction applied to RS92 RAOB data to correct the solar radiationinduced error. Such radiosonde type-dependent difference in the daytime humidity bias needs further investigation into the RAOB sensor property and the correction schemes' difference to the daytime RS92 RAOB temperature and humidity data.

Over the height range above $4.8 \mathrm{~km}$, the mean humidity biases between UCAR or NOAA/STAR COSMIC-2 retrievals and RS41 RAOB are all less than $0.02 \mathrm{~g} \mathrm{~kg}^{-1}$, which suggests that the UCAR or NOAA/STAR COSMIC-2 retrievals both agree well with RS41 RAOB. There is no daytime versus nighttime humidity bias difference for height $>4.8 \mathrm{~km}$. For the comparison with RS92 RAOB, the daytime means humidity biases $\mu\left(\Delta H_{U C A R-R S 92}\right)$ and $\mu\left(\Delta H_{\text {STAR- }}\right.$ ${ }_{R S 92}$ ) are slightly higher than those of nighttime by 0.03 and $0.09 \mathrm{~g} \mathrm{~kg}^{-1}$, respectively. The remnant slight day-night humidity bias difference for height $>4.8 \mathrm{~km}$ might be related to the correction of RS92 temperature and humidity data over this height region.

In Fig. 7, the daytime, nighttime, and dusk/dawn humidity bias uncertainty below $4.2 \mathrm{~km}$ are shown to be much larger than those above $4.2 \mathrm{~km}$. In Figs. $6 \mathrm{a}-\mathrm{b}$, it is shown that the daytime, nighttime, and dusk/dawn humidity bias uncertainty of UCAR or NOAA/STAR COSMIC-2 retrievals versus RS41 comparison are all matched well above 1 $\mathrm{km}$, and there is no day-night dependence. The $\sigma(\Delta H)$ of UCAR wetPf2 versus RS41 RAOB is in general smaller than $\sigma(\Delta H)$ of NOAA/STAR wetPrf versus RS41.

\section{SUMMARY}

This paper compares COSMIC-2 humidity and temperature retrievals processed by UCAR and NOAA/STAR 1DVAR algorithms with collocated Vaisala RS41 and RS92 measurements, respectively. The temperature profile comparisons are focused on the upper troposphere and lower stratosphere regions, while the evaluation of humidity data quality is mainly in the mid and lower troposphere. Both height and SZA dependence on temperature and humidity biases and uncertainties are investigated with collocated COSMIC-2 RO and RS41 and RS92 RAOB data from 1 October 2019 to 30 April 2020. The temperature and 
humidity biases and uncertainties between Vaisala RS41 and RS92 RAOBs are evaluated using COSMIC-2 RO retrievals as a reference. Also, RAOB data are used to assess the differences between COSMIC-2 retrievals from UCAR and NOAA/STAR in terms of temperature and humidity accuracy and uncertainty.

The analysis shows that the UCAR and NOAA/ STAR COSMIC-2 temperature retrievals are, in general, very consistent at height above $12.5 \mathrm{~km}$. Over the height region from 12.5 to $16.5 \mathrm{~km}$, the temperature bias difference among UCAR and NOAA/STAR temperature retrievals and RS41 and RS92 RAOB measurements are minimal (mostly $<0.05 \mathrm{~K})$ with no significant $(<0.05 \mathrm{~K})$ daytime and nighttime difference. This suggests the consistency in temperature data among two COSMIC-2 retrievals and two RAOBs over this height region.

Over the height region between 17.8 and $26.4 \mathrm{~km}$, RS92 RAOB has a warm bias of around $0.1 \mathrm{~K}$ in comparison with RS41 RAOB when using either UCAR or NOAA/ STAR COSMIC-2 temperature retrieval as the reference, which is consistent with previous studies (Ho et al. 2010b) using COSMIC-1 in the comparison. The COSMIC-2 and RS92 analysis shows the RS92 warm biases ( 0.15 $0.24 \mathrm{~K}$ ) mainly during the daytime. Such daytime temperature bias for RS92 may be traceable to the remnant error after applying the correction to the daytime temperature for the RS92 sensor. Compared with UCAR and NOAA/STAR COSMIC- 2 temperature retrievals, there are $\sim 0.1 \mathrm{~K}$ warm biases in the RS41 nighttime measurements over the height from 17.8 to $26.4 \mathrm{~km}$.

Over the height range of $8-11 \mathrm{~km}$, both UCAR and NOAA/STAR COSMIC-2 temperature retrievals are of positive difference (ranging from 0.1 to $0.4 \mathrm{~K}$ ) compared to RS41 and RS92 temperature data. The main difference between UCAR and NOAA/STAR COSMIC-2 temperature retrievals occur over the height range $8-11 \mathrm{~km}$ with a net difference of $\sim 0.1-0.2 \mathrm{~K}$ and NOAA/STAR temperature retrieval being warmer. Such temperature difference can be mainly due to the difference in the 1DVAR retrieval algorithms, particularly the treatment of the a priori model over this height region. We also found that the day-night difference for RS41 and RS92 measurements compared with UCAR retrievals are both small (mean temperature bias difference $<0.1 \mathrm{~K}$ ) over this height region. Comparisons of COSMIC-2 humidity retrievals with RS41 and RS92 RAOBs all show that there are systematic wet biases in the nearsurface (below $4.2 \mathrm{~km}$ ) RAOB humidity data relative to the $\mathrm{RO}$ retrievals, which is consistent with the previous results from the comparison between COSMIC-1 and RAOB observations (Wang et al. 2013). It is shown that UCAR and NOAA/STAR COSMIC-2 humidity retrievals are, in general, very consistent in the troposphere, significantly above $4.2 \mathrm{~km}$ over lands. The mean humidity difference between RS41 and RS92 below $4.2 \mathrm{~km}$ is about $0.07-0.10 \mathrm{~g} \mathrm{~kg}^{-1}$, due to a slight daytime dry bias in RS92 relative to RS41. There is also a clear day-night humidity difference below $4.2 \mathrm{~km}$ in comparing COSMIC-2 retrievals with RS92 RAOBs, mainly due to the daytime RS92 data. The humidity difference below $4.2 \mathrm{~km}$ of UCAR COSMIC-2 versus RS41 RAOB over daytime is very close to those for nighttime.

It is worth noting the temperature bias between 8 to $11 \mathrm{~km}$ that exists between the two retrievals and the consistency between humidity retrievals below $8 \mathrm{~km}$ despite the different retrieval constraint preferences used in each IDVAR algorithm. Such differences in the temperature and humidity retrievals mainly come from the constraints between a priori model and observation in the 1DVAR algorithm. The temperature retrievals are more sensitive to such constraints than the humidity in the lower troposphere. The sensitivity of temperature and humidity retrievals to the differences between 1DVAR algorithms will be further investigated in future studies.

For both temperature and humidity, the uncertainties of UCAR wetPf2 versus RAOB are in general smaller than those of NOAA/STAR wetPrf, with the uncertainty differences being minimum at around $17.8 \mathrm{~km}$ and reaching the maximum at 8 and $30 \mathrm{~km}$, respectively.

The multi-aspect comparison and height/SZA-dependence analysis of COSMIC-2 RO and RS41/RS92 RAOB temperature and humidity data presented in this paper provide comprehensive evaluations of the bias and uncertainty of RAOB data versus RO data, the quality of RO data products processed using different retrieval algorithms and the quality of different types of RAOB measurements. This paper shows the radiosonde sensor-dependent and RO retrieval scheme-dependent difference in the temperature and humidity difference over a certain height and SZA range. The reasons for such differences require further investigation into the difference in the sensor-dependent corrections applied to the RAOB data and the difference between the RO data 1DVAR inversion schemes. With COSMIC-2 being operational and other commercial RO sensors adding more RO data, such multi-aspect inter-comparisons between RO and RAOB data can help improve RO and RAOB data processing quality, which can reduce the uncertainties in the long-term temperature and moisture CDR.

Acknowledgements This study was supported by NOAA grant NA19NES4320002 (Cooperative Institute for Satellite Earth System Studies-CISESS) at the University of Maryland/ESSIC. This work is also partially supported by Technology Maturity Program of NOAA OPPA. The author would like to thank Erin Lynch, Jun Dong, Xin Jing, and Tung-Chang Liu for their inputs during the process of this manuscript. The manuscript contents are solely the opinions of the authors and do not constitute a statement of policy, decision, or position on behalf of NOAA or the U.S. government. 


\section{REFERENCES}

Andrae, U., N. Sokka, and K. Onogi, 2004: The radiosonde temperature bias corrections used in ERA-40. ERA40 Project Report Series, No. 15, ECMWF, Shinfield Park, Reading, 34 pp.

Anthes, R. A., C. Rocken, and Y.-H. Kuo, 2000: Applications of COSMIC to meteorology and climate. Terr. Atmos. Ocean. Sci., 11, 115-156, doi: 10.3319/ TAO.2000.11.1.115(COSMIC). [Link]

Anthes, R. A., P. A. Bernhardt, Y. Chen, L. Cucurull, K. F. Dymond, D. Ector, S. B. Healy, S.-P. Ho, D. C. Hunt, Y.-H. Kuo, H. Liu, K. Manning, C. McCormick, T. K. Meehan, W. J. Randel, C. Rocken, W. S. Schreiner, S. V. Sokolovskiy, S. Syndergaard, D. C. Thompson, K. E. Trenberth, T.-K. Wee, N. L. Yen, and Z. Zeng, 2008: The COSMIC/FORMOSAT-3 Mission: Early Results. Bull. Amer. Meteorol. Soc., 89, 313-334, doi: 10.1175/BAMS-89-3-313. [Link]

Bodeker, G. E., S. Bojinski, D. Cimini, R. J. Dirksen, M. Haeffelin, J. W. Hannigan, D. F. Hurst, T. Leblanc, F. Madonna, M. Maturilli, A. C. Mikalsen, R. Philipona, T. Reale, D. J. Seidel, D. G. H. Tan, P. W. Thorne, H. Vömel, and J. Wang, 2016: Reference Upper-Air Observations for Climate: From Concept to Reality. Bull. Amer. Meteorol. Soc., 97, 123-135, doi: 10.1175/ BAMS-D-14-00072.1. [Link]

Cao, C., W. Wang, E. Lynch, Y. Bai, S. Ho, B. Zhang, 2020: Simultaneous Radio Occultation for Intersatellite Comparison of Bending Angles toward More Accurate Atmospheric Sounding. J. Atmos. Ocean.Technol., 37, 2307-2320, doi: 10.1175/jtech-d-20-0036.1. [Link]

Chen, S.-Y., C.-Y. Liu, C.-Y. Huang, S.-C. Hsu, H.-W. Li, P.-H. Lin, J.-P. Cheng, and C.-Y. Huang, 2021a: An Analysis Study of FORMOSAT-7/COSMIC-2 Radio Occultation Data in the Troposphere. Remote Sens., 13, 717, doi: 10.3390/rs 13040717. [Link]

Chen, Y., X. Shao, C. Cao, and S. Ho, 2021b: Simultaneous Radio Occultation Predictions for Inter-Satellite Comparison of Bending Angle Profiles from COSMIC-2 and GeoOptics. Remote Sens., 13, 3644, doi: 10.3390/ rs13183644. [Link]

Dirksen, R. J., M. Sommer, F. J. Immler, D. F. Hurst, R. Kivi, and H. Vömel, 2014: Reference quality upper-air measurements: GRUAN data processing for the Vaisala RS92 radiosonde. Atmos. Meas. Tech., 7, 44634490, doi: 10.5194/amt-7-4463-2014. [Link]

Forster, P., V. Ramaswamy, P. Artaxo, T. Berntsen, R. Betts, D. W. Fahey, J. Haywood, J. Lean, D. C. Lowe, G. Myhre, J. Nganga, R. Prinn, G. Raga, M. Schulz, and R. Van Dorland, 2007: Changes in Atmospheric Constituents and in Radiative Forcing. In: Solomon, S., D. Qin, M. Manning, Z. Chen, M. Marquis, K. B. Averyt, M. Tignor, and H. L. Miller (Eds.), Climate Change
2007: The Physical Science Basis, Contribution of Working Group I to the Fourth Assessment Report of the Intergovernmental Panel on Climate Change, Cambridge University Press, Cambridge, United Kingdom and New York, NY, USA.

Gaffen, D. J., 1994: Temporal inhomogeneities in radiosonde temperature records. J. Geophys. Res., 99, 36673676, doi: 10.1029/93JD03179. [Link]

Haimberger, L., 2007: Homogenization of radiosonde temperature time series using innovation statistics. J. Clim., 20, 1377-1403, doi: 10.1175/JCLI4050.1. [Link]

Haimberger, L. and U. Andrae, 2011: Radiosonde temperature bias correction in ERA-Interim. ERA Report Series, No. 8, ECMWF, Shinfield Park, Reading, 17 pp.

Haimberger, L., C. Tavolato, and S. Sperka, 2008: Toward elimination of the warm bias in historic radiosonde temperature records-Some new results from a comprehensive intercomparison of upper-air data. J. Clim., 21, 4587-4606, doi: 10.1175/2008JCLI1929.1. [Link]

He, W., S. Ho, H. Chen, X. Zhou, D. Hunt, and Y.-H. Kuo, 2009: Assessment of radiosonde temperature measurements in the upper troposphere and lower stratosphere using COSMIC radio occultation data. Geophys. Res. Lett., 36, L17807, doi: 10.1029/2009GL038712. [Link]

Healy, S., 2020: ECMWF starts assimilating COSMIC-2 data. Available at https://www.ecmwf.int/en/newsletter/163/news/ecmwf-starts-assimilating-cosmic-2-data.

Ho, S.-P. and L. Peng, 2019: Global water vapor estimates from measurements from active GPS RO sensors and passive infrared and microwave sounders. In: Eyvaz, M. and E. Yüksel (Eds.), Green Chemistry Applications, IntechOpen, London, doi: 10.5772/intechopen.79541. [Link]

Ho, S.-P., G. Kirchengast, S. Leroy, J. Wickert, A. J. Mannucci, A. Steiner, D. Hunt, W. Schreiner, S. Sokolovskiy, C. Ao, M. Borsche, A. von Engeln, U. Foelsche, S. Heise, B. Iijima, Y.-H. Kuo, R. Kursinski, B. Pirscher, M. Ringer, C. Rocken, and T. Schmidt, 2009a: Estimating the uncertainty of using GPS radio occultation data for climate monitoring: Intercomparison of CHAMP refractivity climate records from 2002 to 2006 from different data centers. J. Geophys. Res., 114, doi: 10.1029/2009JD011969. [Link]

Ho, S.-P., M. Goldberg, Y.-H. Kuo, C.-Z. Zou, and W. Schreiner, 2009b: Calibration of Temperature in the Lower Stratosphere from Microwave Measurements using COSMIC Radio Occultation Data: Preliminary Results. Terr. Atmos. Ocean. Sci., 20, 87-100, doi: 10.3319/TAO.2007.12.06.01(F3C). [Link]

Ho, S.-P., X. Zhou, Y.-H. Kuo, D. Hunt, and J.-H. Wang, 2010a: Global Evaluation of Radiosonde Water Vapor Systematic Biases using GPS Radio Occultation from COSMIC and ECMWF Analysis. Remote Sens., 2, 
1320-1330, doi: 10.3390/rs2051320. [Link]

Ho, S.-P., Y.-H. Kuo, W. Schreiner, and X. Zhou, 2010b: Using SI-traceable Global Positioning System Radio Occulation Measurements for Climate Monitoring. In: Arndt, D. S., M. O. Baringer, and M. R. Johnson (Eds.), State of the Climate in 2009, Bulletin of the American Meteorological Society, Vol. 91, S36-S37, doi: 10.1175/BAMS-91-7-StateoftheClimate. [Link]

Ho, S.-P., L. Peng, and H. Vömel, 2017: Characterization of the long-term radiosonde temperature biases in the upper troposphere and lower stratosphere using COSMIC and Metop-A/GRAS data from 2006 to 2014. Atmos. Chem. Phys., 17, 4493-4511, doi: 10.5194/acp-174493-2017. [Link]

Ho, S.-P., R. A. Anthes, C. O. Ao, S. Healy, A. Horanyi, D. Hunt, A. J. Mannucci, N. Pedatella, W. J. Randel, A. Simmons, A. Steiner, F. Xie, X. Yue, and Z. Zeng, 2020a: The COSMIC/FORMOSAT-3 Radio Occultation Mission after 12 Years: Accomplishments, Remaining Challenges, and Potential Impacts of COSMIC-2.Bull.Amer. Meteorol.Soc., 101, E1107-E1136, doi: 10.1175/BAMS-D-18-0290.1. [Link]

Ho, S.-P., X. Zhou, X. Shao, B. Zhang, L. Adhikari, S. Kireev, Y. He, J. G. Yoe, W. Xia-Serafino, and E. Lynch, 2020b: Initial Assessment of the COSMIC-2/ FORMOSAT-7 Neutral Atmosphere Data Quality in NESDIS/STAR Using In Situ and Satellite Data. Remote Sens., 12, 4099, doi: 10.3390/rs12244099. [Link]

Ho, S., X. Shao, B. Zhang, X. Zhou, J. Dong, and S. Kireev, 2022: NESDIS STAR GNSS RO Processing, Validation, and Monitoring System: Initial Validation of the STAR COSMIC-2 Data. (Submitted)

Jauhiainen, H., P. Survo, R. Lehtinen, and J. Lentonen, 2014: Radiosonde RS41 and RS92 key differences and comparison test results in different locations and climates. TECO-2014 WMO Technical Conference on Meteorological and Environmental Instruments and Methods of Observations, Saint Petersberg, Russian, P3.

Jensen, M. P., D. J. Holdridge, P. Survo, R. Lehtinen, S. Baxter, T. Toto, and K. L. Johnson, 2016: Comparison of Vaisala radiosondes RS41 and RS92 at the ARM Southern Great Plains site. Atmos. Meas. Tech., 9, 3115-3129, doi: 10.5194/amt-9-3115-2016. [Link]

Kawai, Y., M. Katsumata, K. Oshima, M. E. Hori, and J. Inoue, 2017: Comparison of Vaisala radiosondes RS41 and RS92 launched over the oceans from the Arctic to the tropics. Atmos. Meas. Tech., 10, 2485-2498, doi: 10.5194/amt-10-2485-2017. [Link]

Kursinski, E. R. and G. A. Hajj, 2001: A comparison of water vapor derived from GPS occultations and global weather analyses. J. Geophys. Res., 106, 1113-1138, doi: 10.1029/2000JD900421. [Link]

Leiterer, U., H. Dier, and T. Naebert, 1997: Improvements in radiosonde humidity profiles using RS80/RS90 radiosondes of Vaisala. Contributions to Atmospheric Physics, 70, 319-336.

Luers, J. K., 1997: Temperature error of the Vaisala RS90 radiosonde. J. Atmos. Ocean. Technol., 14, 1520-1532, doi: 10.1175/1520-0426(1997)014<1520:TEOTVR>2 .0.CO;2. [Link]

Luers, J. K. and R. E. Eskridge, 1995: Temperature corrections for the VIZ and Vaisala radiosondes. $J$. Appl. Meteorol. Climatol., 34, 1241-1253, doi: 10.1175/1520-0450(1995)034<1241:TCFTVA > 2.0 . $\mathrm{CO} ; 2$. [Link]

Luers, J. K. and R. E. Eskridge, 1998: Use of radiosonde temperature data in climate studies. J. Clim., 11, 10021019,doi: 10.1175/1520-0442(1998)011<1002:UORT$\mathrm{DI}>2.0 . \mathrm{CO} ; 2$. [Link $]$

Schreiner, W. S., J. P. Weiss, R. A. Anthes, J. Braun, V. Chu, J. Fong, D. Hunt, Y.-H. Kuo, T. Meehan, W. Serafino, J. Sjoberg, S. Sokolovskiy, E. Talaat, T. K. Wee, and Z. Zeng, 2020: COSMIC-2 Radio Occultation Constellation: First Results. Geophys. Res. Lett., 47, e2019GL086841, doi: 10.1029/2019GL086841. [Link]

Seidel, D. J., F. H. Berger, H. J. Diamond, J. Dykema, D. Goodrich, F. Immler, W. Murray, T. Peterson, D. Sisterson, M. Sommer, P. Thorne, H. Vomel, and J. Wang, 2009: Reference upper-air observations for climate: Rationale, progress, and plans. Bull. Amer. Meteorol. Soc., 90, 361-369, doi: 10.1175/2008BAMS2540.1. [Link]

Shao, H., 2020: JCSDA Support Leading to the Implementation of Operational Assimilation of COSMIC-2 Data. Available at https://www.jcsda.org/ news-blog/2020/6/2/jcsda-support-leading-to-the-implementation-of-operational-assimilation-of-cosmic2-datanbsp.

Shao, X., S. Ho, B. Zhang, C. Cao, and Y. Chen, 2021: Consistency and Stability of SNPP ATMS Microwave Observations and COSMIC-2 Radio Occultation over Oceans. Remote Sens., 13, 3754, doi: 10.3390/ rs13183754. [Link]

Sherwood, S. C., C. L. Meyer, R. J. Allen, and H. A. Titchner, 2008: Robust tropospheric warming revealed by iteratively homogenized radiosonde data. J. Clim., 21, 5336-5352, doi: 10.1175/2008JCLI2320.1. [Link]

Solomon, S., D. Qin, M. Manning, Z. Chen, M. Marquis, K. B. Averyt, M. Tignor, and H. L. Miller, 2007: Climate Change 2007: The Physical Science Basis, Contribution of Working Group I to the Fourth Assessment Report of the Intergovernmental Panel on Climate Change, Cambridge University Press, Cambridge, United Kingdom and New York, NY, USA, 996 pp.

Sun, B., A. Reale, D. J. Seidel, and D. C. Hunt, 2010: Comparing radiosonde and COSMIC atmospheric profile 
data to quantify differences among radiosonde types and the effects of imperfect collocation on comparison statistics. J. Geophys. Res., 115, D23104, doi: 10.1029/2010JD014457. [Link]

Sun, B., A. Reale, S. Schroeder, D. J. Seidel, and B. Ballish, 2013: Toward improved corrections for radiationinduced biases in radiosonde temperature observations. J. Geophys. Res., 118, 4231-4243, doi: 10.1002/ jgrd.50369. [Link]

Sun, B., T. Reale, S. Schroeder, M. Pettey, and R. Smith, 2019: On the accuracy of Vaisala RS41 versus RS92 upper-air temperature observations. J. Atmos. Ocean. Technol., 36, 635-653, doi: 10.1175/JTECHD-18-0081.1. [Link]

Thorne, P. W., P. Brohan, H. A. Titchner, M. P. McCarthy, S. C. Sherwood, T. C. Peterson, L. Haimberger, D. E. Parker, S. F. B. Tett, B. D. Santer, D. R. Fereday, and J. J. Kennedy, 2011: A quantification of uncertainties in historical tropical tropospheric temperature trends from radiosondes. J. Geophys. Res., 116, D12116, doi: 10.1029/2010JD015487. [Link]

Turner, D. D., B. M. Lesht, S. A. Clough, J. C. Liljegren, H. E. Revercomb, and D. C. Tobin, 2003: Dry bias and variability in Vaisala RS80-H radiosondes: The ARM experience. J. Atmos. Ocean. Technol., 20, 117-132, doi: 10.1175/1520-0426(2003)020<0117:DBAVIV >2 .0.CO;2. [Link]

Vömel, H., H. Selkirk, L. Miloshevich, J. Valverde-Canos- sa, J. Valdés, E. Kyrö, R. Kivi, W. Stolz, G. Peng, and J. A. Diaz, 2007: Radiation dry bias of the Vaisala RS92 humidity sensor. J. Atmos. Ocean. Technol., 24, 953-963, doi: 10.1175/JTECH2019.1. [Link]

Wang, B.-R., X.-Y. Liu, and J.-K. Wang, 2013: Assessment of COSMIC radio occultation retrieval product using global radiosonde data. Atmos. Meas. Tech., 6, 10731083, doi: 10.5194/amt-6-1073-2013. [Link]

Wang, J. and L. Zhang, 2008: Systematic errors in global radiosonde precipitable water data from comparisons with ground-based GPS measurements. J. Clim., 21, 2218-2238, doi: 10.1175/2007JCLI1944.1 . [Link]

Wang, J., H. L. Cole, D. J. Carlson, E. R. Miller, K. Beierle, A. Paukkunen, and T. K. Laine, 2002: Corrections of humidity measurement errors from the Vaisala RS80 radiosonde-Application to TOGA COARE data. J. Atmos. Ocean. Technol., 19, 981-1002, doi: 10.1175/1520-0426(2002)019<0981:COHMEF $>2.0$. $\mathrm{CO} ; 2$. [Link]

Wee, T.-K., 2018: A variational regularization of Abel transform for GPS radio occultation. Atmos. Meas. Tech., 11, 1947-1969, doi: 10.5194/amt-11-19472018. [Link]

Xue, Y., J. Li, W. P. Menzel, E. Borbas, S.-P. Ho, Z. Li, and J. Li, 2019: Characteristics of satellite sampling errors in total precipitable water from SSMIS, HIRS, and COSMIC observations. J. Geophys. Res., 124, 69666981, doi: 10.1029/2018JD030045. [Link] 